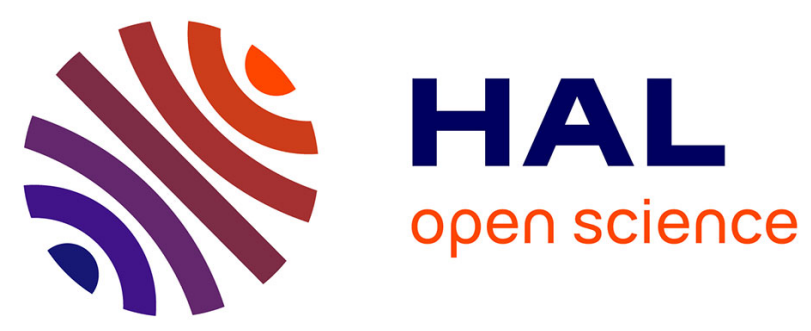

\title{
New insights into the substrate specificity of macrophage elastase MMP-12
}

Anne-Sophie Lamort, Rodolphe Gravier, Anni Laffitte, Luiz Juliano, Marie-Louise Zani, Thierry Moreau

\section{To cite this version:}

Anne-Sophie Lamort, Rodolphe Gravier, Anni Laffitte, Luiz Juliano, Marie-Louise Zani, et al.. New insights into the substrate specificity of macrophage elastase MMP-12. Biological Chemistry, 2016, 397 (5), pp.469-484. 10.1515/hsz-2015-0254 . hal-01398704

\section{HAL Id: hal-01398704 https://u-bourgogne.hal.science/hal-01398704}

Submitted on 27 May 2020

HAL is a multi-disciplinary open access archive for the deposit and dissemination of scientific research documents, whether they are published or not. The documents may come from teaching and research institutions in France or abroad, or from public or private research centers.
L'archive ouverte pluridisciplinaire HAL, est destinée au dépôt et à la diffusion de documents scientifiques de niveau recherche, publiés ou non, émanant des établissements d'enseignement et de recherche français ou étrangers, des laboratoires publics ou privés.

\section{다(1)(2)}

Distributed under a Creative Commons Attribution - ShareAlikel 4.0 International 


\section{Biological Chemistry 'Just Accepted' Papers}

Biological Chemistry 'Just Accepted' Papers are papers published online, in advance of appearing in the print journal. They have been peer-reviewed, accepted and are online published in manuscript form, but have not been copy edited, typeset, or proofread. Copy editing may lead to small differences between the Just Accepted version and the final version. There may also be differences in the quality of the graphics. When papers do appear in print, they will be removed from this feature and grouped with other papers in an issue.

Biol Chem 'Just Accepted' Papers are citable; the online publication date is indicated on the Table of Contents page, and the article's Digital Object Identifier (DOI), a unique identifier for intellectual property in the digital environment (e.g., $10.1515 / \mathrm{hsz}-2011-\mathrm{xxxx}$ ), is shown at the top margin of the title page. Once an article is published as Biol Chem 'Just Accepted' Paper (and before it is published in its final form), it should be cited in other articles by indicating author list, title and DOI.

After a paper is published in Biol Chem 'Just Accepted' Paper form, it proceeds through the normal production process, which includes copy editing, typesetting and proofreading. The edited paper is then published in its final form in a regular print and online issue of Biol Chem. At this time, the Biol Chem 'Just Accepted' Paper version is replaced on the journal Web site by the final version of the paper with the same DOI as the Biol Chem 'Just Accepted' Paper version.

\section{Disclaimer}

Biol Chem 'Just Accepted' Papers have undergone the complete peer-review process. However, none of the additional editorial preparation, which includes copy editing, typesetting and proofreading, has been performed. Therefore, there may be errors in articles published as Biol Chem 'Just Accepted' Papers that will be corrected in the final print and online version of the Journal. Any use of these articles is subject to the explicit understanding that the papers have not yet gone through the full quality control process prior to advanced publication. 


\section{Research Article}

\section{New insights into the substrate specificity of macrophage elastase MMP-12}

Anne-Sophie Lamort ${ }^{1}$, Rodolphe Gravier ${ }^{1, \mathrm{a}}$, Anni Laffitte ${ }^{1, \mathrm{~b}}$, Luiz Juliano ${ }^{2}$, Marie-Louise Zani $^{1}$ and Thierry Moreau ${ }^{1, *}$

${ }^{1}$ CEPR UMR INSERM U1100, Equipe 2 Mécanismes Protéolytiques dans 1'Inflammation, Faculté de Médecine, Université de Tours, 10 Bd. Tonnellé, F-37032 Tours Cedex, France

${ }^{2}$ Escola Paulista de Medicina, Université de Sao Paulo, 04044-020 Sao Paulo, Brazil

*Corresponding author

e-mail: thierry.moreau@univ-tours.fr

${ }^{a}$ Current address: Atlanbio, Z.I. de Brais - 1 rue Graham Bell, F-44600 Saint Nazaire, France

${ }^{\mathrm{b}}$ Current address: INRA UMR1324, CNRS UMR6265, Centre des Sciences du Goût et de l'Alimentation, Université de Bourgogne, F-21000 Dijon, France 


\begin{abstract}
Macrophage elastase, or MMP-12, is mainly produced by alveolar macrophages and is believed to play a major role in the development of chronic obstructive pulmonary disease (COPD). The catalytic domain of MMP-12 is unique among MMPs in that it is quite highly active on numerous substrates including elastin. However, measuring MMP-12 activity in biological fluids has been hampered by the lack of highly selective substrates. We therefore synthesized four series of fluorogenic peptide substrates based on the sequences of MMP-12 cleavage sites in its known substrates. Human MMP-12 efficiently cleaved peptide substrates containing a Pro at P3 in the sequence Pro-X-X $\downarrow$ Leu but lacked selectivity towards these substrates compared to other MMPs, including MMP-2, MMP-7, MMP-9 and MMP-13. In contrary, the substrate Abz-RNALAVERTAS-EDDnp derived from the CXCR5 chemokine was the most selective substrate for MMP-12 ever reported. All substrates were cleaved more efficiently by full-length MMP-12 than by its catalytic domain alone, indicating that the Cterminal hemopexin domain influences substrate binding and/or catalysis. Docking experiments revealed unexpected interactions between the peptide substrate AbzRNALAVERTAS-EDDn and MMP-12 residues. Most of our substrates were poorly cleaved by murine MMP-12 suggesting that human and murine MMP-12 have different substrate specificities despite their structural similarity.
\end{abstract}

Keywords: MMP-12; macrophage elastase; enzyme specificity; substrate recognition; peptide-protein docking. 


\section{Introduction}

Macrophage elastase, or MMP-12, is predominantly produced by activated macrophages at sites of inflammation (Shapiro et al., 1993), although both resting and actived monocytederived dendritic cells also synthesize this protease (Kis-Toth et al., 2013). Some other cell types, including human bronchial epithelial cells, also synthesize and secrete MMP-12, but in much smaller quantities (Lavigne et al., 2004). MMP-12 has many features typical of MMPs, including its secretion as an activatable proform, its domain structure and the location of its encoding gene within the MMP gene cluster on chromosome 11 (Kaynar et al., 2012). Like other MMPs, it can break down a wide variety of ECM substrates, including elastin, types I, II, and IV collagens (but not fibrillar collagens) as well as fibronectin, laminin and non-ECM proteins (see ref (Kaynar and Shapiro, 2012) for a review) such as pro-TNF- $\alpha$, plasminogen and CXC chemokines (Dean et al., 2008).

Studies carried out in the early 1980s showed that $\alpha$ 1-PI ( $\alpha$-1-proteinase inhibitor, sometimes called $\alpha$ 1-anti-trypsin) is readily cleaved by MMP-12, which results in inactivation of the inhibitor (Banda et al., 1980). This result suggested that MMP-12, by directly and indirectly enhancing the elastinolytic/proteolytic potential of neutrophilic and macrophagic cells, played a pivotal role in the pathology of lung diseases especially chronic obstructive pulmonary disease (COPD) (Banda et al., 1980). This was because $\alpha$ 1-PI is the predominant inhibitor of neutrophil elastase in vivo and most MMP-12 substrates are associated with the ECM. In keeping with this hypothesis, Shapiro's group later demonstrated that macrophages of MMP-12-deficient mice are significantly poorer at breaking down ECM substrates (Shipley et al., 1996) than those of wild type mice. In addition, they also showed that these MMP-12-/mice are resistant to lung emphysema induced by prolonged exposure to tobacco smoke (Hautamaki et al., 1997). However, it is difficult to extrapolate these findings to humans and the alleged involvement of MMP-12 in human COPD/emphysema is still debated, despite evidence that the MMP-12 gene is activated by cigarette smoking and is highly expressed in patients with COPD (Demedts et al., 2006; Molet et al., 2005). Other authors have shown that in human, the increase in matrix-degrading proteases of macrophagic origin in the emphysematous lung does not result from an increase in MMP-12 synthesis/secretion, but rather from the increased production of other MMPs (Finlay et al., 1997). Similarly, the results of numerous genetic studies indicate that several single nucleotide polymorphisms (SNP) in the MMP-12 gene are likely to be associated with the prevalence of COPD 
(Haq et al., 2011; Hunninghake et al., 2009; Wallace et al., 2002), while other studies have not associated MMP-12 gene polymorphism with the prevalence or severity of COPD (Schirmer et al., 2009; Zhou et al., 2013). MMP-12 can also, like many other MMPs, generate active biological fragments (matrikines) from ECM proteins, as well as having a direct role in lung matrix degradation. For example, the fragments resulting from the breakdown of elastin and tropo-elastin by MMP-12 (Heinz et al., 2010; Taddese et al., 2009) have chemotactic properties in mice (Houghton et al., 2006); they help recruit monocytes to lung tissue and thus contribute to perpetuating lung inflammation.

MMP-12 is thought to be associated with other pathological conditions, such as rheumatoid arthritis (Liu et al., 2004; Wang et al., 2004), atherosclerosis (Matsumoto et al., 1998) and aortic aneurysm (Curci et al., 1998), in addition to its role in lung disease. The classical picture of MMPs secreted as proforms that are activated and then digest various substrates has been expanded recently. Indeed, MMP-12 seems to have a novel unexpected role in regulating antiviral immunity. The protease may enter the nucleus of a virus-infected cell where it serves as a transcription factor driving the transcription of the I $\kappa \mathrm{B} \alpha$ gene. This results in the secretion of the antiviral molecule interferon-alpha. The second, distinct role of MMP-12 in antiviral immunity is to proteolytically clear interferon-alpha from the blood, so allowing the virus-induced inflammation to be resolved (Marchant et al., 2014).

Selectively measuring MMP-12 enzyme activity in complex biological fluids is a challenge. The two main reasons are that the concentration of MMP-12 is often much lower than that of other related MMPs like MMP-2 and MMP-9, and that MMPs have closely related catalytic clefts, which results in highly redundant substrate recognition. The synthetic substrates currently available are not sufficiently selective for determining MMP-12 activity, especially - though not exclusively - in the presence of MMP-2 and MMP-9. We have therefore developed four series of internally quenched fluorogenic substrates whose peptide sequences are based on the sequences of sites in MMP-12 natural substrates cleaved by the protease. Although most substrates were readily cleaved by other MMPs, including MMP-2, MMP-7, MMP-9 and MMP-13, we identified one substrate derived from the chemokine CXCL5 that was highly selective for human MMP-12. Our results also shed new light on the enzyme specificity of MMP-12. 


\section{Results}

\section{Designing selective substrates for human MMP-12}

There are many commercially available substrates for most MMPs, including MMP-12, but few of them are highly selective for a given MMP. The fluorogenic substrate Mca-PLGLDpa-AR with Mca (methylcoumarin) as fluorescent group and Dpa (N-3-(2,4-dinitrophenyl)L-2,3-diaminopropionyl)) as quencher group, was originally designed by Knight et al. (1992) and is frequently used to measure MMP-12 activity. It was later modified and a Glu-Glu (EE) sequence was introduced (Mca-PLGLEEA-Dpa- $\mathrm{NH}_{2}$ ) to enhance selectivity for MMP-12 (Devel et al., 2006). Although this substrate was claimed to be selective for MMP-12, MMP-13 and MMP-9 also seem to cleave it efficiently: their $\mathrm{k}_{\mathrm{cat}} / K_{\mathrm{m}}$ values indicate that they are only 3.5-fold (MMP-13) and about 6-fold (MMP-9) less active than MMP-12. Thus this substrate may be unsuitable for detecting and quantifying MMP-12 activity in biological fluids, where MMP-12 is often accompanied by higher concentrations of MMP-9 and other MMPs, even if it were used to design a FRET probe supposed to be selective for MMP-12 (Cobos-Correa et al., 2009), to visualize its activity in vivo. Our analysis of the occurrence of each amino acid in the region surrounding the cleavage sites of a variety of MMP-12 substrates resulted in a consensus peptide sequence that retained key amino acids at each position on either side of the cleavage site. This peptide should be selectively cleaved by MMP-12. Because some amino acids (e.g Ala, Gly, Val, Pro) are over-represented in structural proteins and/or proteins of the ECM that are substrates for several MMPs including MMP-12, we performed our sequence analysis on two different sets of protein substrates, one including soluble, globular proteins and the other comprising structural and ECM proteins. We determined the frequency of each amino acid from position P4 to P4' (Figure 1) within each of 74 unique cleavage sites in 44 distinct soluble MMP-12 substrates, including synthetic substrates and 176 cleavage sites in 16 structural substrates like elastin (see Supplementary Information, Table S1). Analysis of correlated mutations in the regions surrounding the cleavage sites gave no significant matches between residues, possibly because of the relatively few sequences analyzed. However visual inspection of these sequences revealed that a Pro at P3 was often correlated with a Leu at P1'. We made no corrections to account for the frequency of all 20 amino acids in each substrate for two reasons. First, it was inappropriate for the small, synthetic substrates included in our study and second because we 


\section{Substrate specificity of MMP-12}

assumed that the cleavage site is recognized as such regardless of the amino acids in other regions of the protein substrate.

These analyses of soluble substrates gave us the consensus substrate peptide sequence RPLALWRS and analysis of the "insoluble " ones gave the sequence GPAGLGGA (Figure 1). This latter sequence was not exploited because it had low complexity content and hence was unlikely to provide a selective substrate for MMP-12. The fluorogenic peptide Abz-RPLALWRSQ-EDDnp (PJ-1) was synthesized and used as the lead substrate for synthesising substrates modified at different positions to increase selectivity or to obtain structure-function information (Table 1). For example, we introduced a negatively charged residue, glutamate, at position P4 in PP-21 substrate to evaluate the effect of the positively charged arginine at P4 on substrate hydrolysis. We also replaced the Pro at P3 by a Gly residue in PP-23 in order to assess the importance of proline at that position.

The second substrate series (Group II) is based on the lead sequence PLGLEEA used to synthesize PP-2b. This sequence, which is said to be efficiently cleaved by MMP-12, is also hydrolysed by MMP-9 and MMP-13 with similarly activity. It was optimized to attempt to generate a substrate cleaved only by MMP-12 (Table 1).

The third series of fluorogenic substrates (Group III) is based on a consensus sequence that takes into account the amino acids most frequent at each position in both soluble and insoluble substrates. This generated the PP-6 substrate containing the sequence RPLGLGGAQ, which was then modified to give two additional PP-6-derived substrates (Table 1).

The last series of fluorogenic substrates tested was based on sequences spanning MMP-12 cleavage sites in proteins reported to be physiological substrates of MMP-12. The 13-mer PP-17 substrate contains both a Phe-Leu and a Pro-Met bond. The former corresponds to the Phe 352-Leu 353 scissile bond in human $\alpha 1$-PI cleaved preferentially by human MMP-12 (Gronski et al., 1997), while the latter corresponds to the Pro 357 - Met 358 bond in human a1-PI cleaved by mouse MMP-12 (Banda et al., 1987). It is noteworthy that oxidation of a1-PI led to a shift in the mouse MMP-12 cleavage site, with the Phe 352 - Leu 353 bond becoming most susceptible, most probably as a consequence of the oxidation of Met 358 (Banda et al., 1987). For other substrates of this series (PP-14, PP-15, PP-16), we used the amino-acid sequence derived from the MMP-12 cleavage sites in two CXC chemokines 
(Dean, Cox et al. 2008) one site in CXCL1 and two sites in CXCL5. Although ELR ${ }^{+}$CXC chemokines may be activated or inactivated by various MMPs, MMP-12 seems to target specific sites (Dean, Cox et al. 2008) that are different from those attacked by other MMPs. Hence peptide sequences based on these proteolytic sites may be used to design a selective MMP-12 substrate.

All 21 of the above peptides were synthesized as short internally quenched fluorescent peptides bearing an $\mathrm{Abz}$ fluorescent group at the N-terminus and an EDDnp at the C-terminus. The kinetics of their MMP-12-mediated cleavage were analyzed.

\section{Characterization of fluorogenic substrates for human and murine MMP-12}

We first determined the $k_{\text {cat }} / K_{m}$ ratios for substrate hydrolysis by MMP-12 from direct fluorescence measurements using a low substrate concentration so that hydrolysis obeyed first-order kinetics $\left(\mathrm{S}<<K_{\mathrm{m}}\right)$. The individual parameters $K_{m}$ and $V_{\mathrm{m}}$ were also determined by fitting data to the Michaelis-Menten equation using non-linear regression analysis. We then calculated $k_{\text {cat }}$ from the equation $V_{\mathrm{m}}=k_{\text {cat }} \mathrm{x}[\mathrm{E}]_{\mathrm{t}}$ where $[\mathrm{E}]_{\mathrm{t}}$ is the active enzyme concentration as determined from active-site titration. Because Abz-peptidyl-EDDnp substrates exhibit an inner filter effect at high concentrations leading to a decrease of fluorescence yield proportional to the increase of peptide concentration, we did not use substrate concentrations above $20 \mu \mathrm{M}$ (Korkmaz et al., 2008). Hence, we determined individual kinetic parameters only for those substrates that were efficiently cleaved as assessed by their $k_{\text {cat }} / K_{\mathrm{m}}$ value (Table 2).

For some substrates, there were discrepancies of differing importance between the $k_{\text {cat }} / K_{\mathrm{m}}$ calculated from individual parameters $k_{\text {cat }}$ and $K_{\mathrm{m}}$ and those same $k_{\mathrm{cat}} / K_{\mathrm{m}}$ ratios determined directly (first order conditions). We have previously seen such differences for this type of substrates and attribute them to the fact that substrate concentration was determined spectrophotometrically using the molar extinction coefficient of the EDDnp group. This extinction coefficient could be different for the whole substrate, depending on its peptide sequence, possibly resulting in the under- or over-estimation of substrate concentrations. This may affect $K_{\mathrm{m}}$ determination using the Michaelis-Menten fit but not the directly determined $k_{\text {cat }} / K_{\mathrm{m}}$ value which depends only on the enzyme concentration, not on substrate concentration. 
All the substrates in the first series containing the lead consensus sequence PJ-1 and its variants (group I), were cleaved by both the catalytic domain and the full-length form of human MMP-12 at the peptide bond N-terminal to the central leucine residue, confirming the strong preference of MMP-12 for this residue at P1'. All the substrates except PP-23, contained a second Leu in the motif Pro-Leu, but this Pro-Leu bond was almost never cleaved, suggesting that the Pro residue influences the peptide conformation to foster efficient catalysis at the peptide bond where the second Leu occupies the S1' subsite of the enzyme. Replacing Pro with Gly in the substrate PP-23 dramatically decreased the $k_{\text {cat }} / K_{\mathrm{m}}$ although the major cleavage site was still at the Ala-Leu bond. Also, modifying the sequence on the C-terminal side of the scissile Ala-Leu bond in PJ-1-derived substrates did not alter the major cleavage sites from the Ala-Leu or Glu-Leu bonds (PJ-5). The data for the second and third series of substrates confirmed the importance of the Pro at P3 position for directing cleavage at the appropriate bond. The Pro-Leu bond was not cleaved despite the marked preference of MMP-12 for a Leu at P1'; the Gly-Leu or Glu-Leu bonds were almost invariably cleaved instead. We detected no differences between the locations of sites cleaved by the catalytic domain and the full-length forms of human MMP-12. Although the MMP-12 catalytic domain appeared to be catalytically active, the $k_{\text {cat }} / K_{\mathrm{m}}$ values for substrate hydrolysis by full-length MMP-12 were significantly greater (6-times for PP-20 and PP-6 and up to 35-times for PJ-3) than those for the catalytic domain alone. This result confirms early reports that the MMP-12 catalytic domain alone can hydrolyse elastin (Curci et al., 1998) and collagen (Taddese et al., 2009) without the contribution of the hemopexin-like domain. It also shows that full-length MMP-12 is much more efficient at cleaving substrates, even small ones. All the substrates in the first three series, except PP-23, were hydrolysed with $k_{\text {cat }} / K_{\mathrm{m}}$ values of about 4 to $80 \mathrm{mM}^{-1}$ $\mathrm{s}^{-1}$. PP-23 appears to be a rather poor substrate for both forms of human MMP-12. The fourth substrate series comprising sequences spanning cleavage sites in natural substrates of MMP-12, human $\alpha 1$-PI, human CXCL1 and murine CXCL5, provided less efficient substrates for human MMP-12 in terms of $k_{\mathrm{cat}} / K_{\mathrm{m}}$ compared to group I, II and III ; however PP-16 proved to be very selective for human MMP-12 (see below).

Remarkably, our attempts to identify sensitive substrates for MMP-12 based on consensus amino acid sequences generated the best substrates in our four groups. The lead sequence PJ-1 was cleaved efficiently by full-length MMP-12 with a $k_{\text {cat }} / K_{\mathrm{m}}$ ratio of $920 \mathrm{mM}^{-1} \mathrm{~s}^{-1}$, while the value for PJ-1 hydrolysis by h-CAT-MMP-12 (catalytic domain of human MMP-12) was the highest $\left(80 \mathrm{mM}^{-1} \mathrm{~s}^{-1}\right)$ among all the substrates tested. Modifying the PJ-1 sequence by 
introducing Arg at P2' (PJ-4) or Glu at P1 (PJ-5) did not significantly alter cleavage efficiency. The Glu-Glu in PJ-8 provided the best substrate for human MMP-12, with a $k_{\mathrm{cat}} / K_{\mathrm{m}}$ of $1600 \mathrm{mM}^{-1} \mathrm{~s}^{-1}$. This is about 2-times greater than that for PJ-1. PP-2b, which contains the PLGLEEA sequence, was cleaved with a $k_{\text {cat }} / K_{\mathrm{m}}$ ratio of $110 \mathrm{mM}^{-1} \mathrm{~s}^{-1}$. This value is almost identical to that for Mca-PLGLEEA-Dpa- $\mathrm{NH}_{2}$, a widely used substrate for human MMP-12 that is cleaved with a $k_{\text {cat }} / K_{\mathrm{m}}$ of $185 \mathrm{mM}^{-1} \mathrm{~s}^{-1}$ (Devel et al., 2006), despite the fact that they have different reporter-quencher pairs (Abz-EDDnp and Mca-Dpa- $\mathrm{NH}_{2}$ ). Our substrates PJ-8 and PJ-1 appear to be the best substrates ever reported for human MMP-12 regardless of cleavage selectivity. PJ-8 is 15 -times better than PP-2b and PJ-1 is 8-times better than PP-2b, the substrate containing the PLGLEEA sequence. Inserting an Arg residue at P4 in PP-2b increased the $k_{\mathrm{cat}} / K_{\mathrm{m}}$ of PP-2 hydrolysis 6-fold. Most good substrates in the first, PJ-1-derived, series also had an Arg at P4, suggesting that the S4 subsite of the enzyme is important for defining substrate specificity.

Because the mouse is an appropriate model for studying lung diseases, we also tested our substrates with mouse MMP-12, either the catalytic domain alone or the full-length enzyme. Surprisingly, most of them were poor or very poor substrates of both forms of mouse MMP-12. The exception was PP-22, which was cleaved 4-times less efficiently by the full-length mouse MMP-12 than by human FL-MMP-12 (Table 2). However, PP-22 $\left(k_{\text {cat }} / K_{\mathrm{m}}\right.$ : $\left.145 \mathrm{mM}^{-1} \mathrm{~s}^{-1}\right)$ may be useful for evaluating the activity of mouse MMP-12 in murine biological fluids, provided it is present as a full-length form enzyme. These results suggest that the substrate specificity of mouse MMP-12 may differ from that of its human counterpart. This is supported by the observation that human $\alpha 1-\mathrm{PI}$, a proteinase inhibitor said to be a natural substrate of MMP-12, is cleaved in its inhibitory reactive loop by both human and murine MMP-12. Cleavage is probably not at the same peptide bond because the SDS-PAGE degradation patterns were slightly different (data not shown).

\section{Human full-length MMP-12 has a better catalytic efficiency than the catalytic domain alone}

The $k_{\mathrm{cat}} / K_{\mathrm{m}}$ values for hydrolysis of our 21 substrates indicate that full-length MMP-12 is significantly more active than the catalytic domain alone. To rule out the possibility that the histidine tag (6× His) of the catalytic domain of MMP-12 may have an influence on the binding and/or catalysis of our substrates, we determined $k_{\text {cat }} / K_{\mathrm{m}}$ values for the hydrolysis of representative substrates in each series by commercial non tagged catalytic domain of human 
MMP-12. We found no significative differences for the hydrolysis of PJ-1, PJ-8, PP-2, PP-2b, PP-6 and PP-16 by non tagged CAT-MMP-12 versus His-tagged CAT-MMP-12. This suggests that the C-terminal His-tag, located opposite to the protease active site does not interfere with the enzyme activity of the MMP-12 catalytic domain.

Then we determined individual kinetic parameters using classical non-linear regression analysis to evaluate the effects of targeted amino acid changes in some substrates on catalytic efficiency $\left(k_{\text {cat }}\right)$ or substrate affinity $\left(K_{\mathrm{m}}\right)$ (Table 3$)$. Except PJ-8 for which a marked decrease of the $K_{m}$ value (about 4-times lower) was observed for h-FL-MMP-12 compared to h-CAT-MMP-12, $\mathrm{K}_{m}$ values were between $5 \mu \mathrm{M}$ and $30 \mu \mathrm{M}$ depending on the substrate, but did not vary significantly between both forms of the human enzyme for a given substrate. Thus, amino acid changes within PJ-1 and PP-2b peptide lead sequences of most substrates do not greatly alter substrate affinity and the C-terminal hemopexin-like domain has little influence on the binding affinity of the substrate. The Glu-Glu motif in PJ-8 and PP-2b resulted in the lowest $K_{\mathrm{m}}$ values with h-FL-MMP-12, although this was not the case for PP-2, which has just an additional Arg residue on its N-terminal side (Table 3). Replacing either Glu with a bulky hydrophobic Trp residue or a positively charged Arg residue had no deleterious influence on substrate affinity. Perhaps residues P2' and P3' are less important for substrate affinity than the Leu at P1' and Pro-Leu at P3-P2, which seem to be essential for maximum substrate binding affinity. The relative catalytic efficiencies of h-FL-MMP-12 and h-CAT-MMP-12 indicate that the greater $k_{\text {cat }} / K_{\mathrm{m}}$ for a given substrate hydrolysed with h-FL-MMP-12 compared to h-CAT-MMP-12 is predominantly driven by an increase in $k_{\text {cat }}$. The $k_{\text {cat }}$ values for other substrates hydrolyzed by full-length MMP-12 were significantly higher (10 to 25 times) than those for the catalytic domain, i.e approximately one order of magnitude. This suggests that even for small-sized synthetic substrates, the hemopexin-like domain of MMP-12 may help to properly position the substrate for optimal catalysis, however by yet unknown mechanisms.

\section{Selectivity of MMP-12 substrates}

All the substrates in groups I, II and III, except PP-23, have a Pro-X-X- $\downarrow-X_{H Y}$ motif, where $\mathrm{X}_{\mathrm{HY}}$ is a hydrophobic residue (e.g leucine) that is recognized by a number of MMPs. We determined the $k_{\text {cat }} / K_{\mathrm{m}}$ values for their hydrolysis by several MMPs (e.g: MMP-2, MMP-7, MMP-9 and MMP-13) that are likely to be co-localized with MMP-12 in tissues like the lung. Most group I substrates were better substrates for MMP-12 than they were for MMP-2, 
MMP-7 or MMP-9, with selectivity ratios $\left(k_{\mathrm{cat}} / K_{\mathrm{m}}\right.$ with MMP-12 / $k_{\mathrm{cat}} / K_{\mathrm{m}}$ with MMP-x $)$ of approximately 2 (PJ-4 with MMP-2) to 460 (PJ-1 with MMP-9). MMP-13 appeared to be much more active on these substrates. MMP-13 hydrolysed some of them as actively as MMP-12 (PJ-1 and PP-21), but was significantly more efficient towards PP-22 (selectivity ratio: 0.12) and PP-20 (selectivity ratio: 0.3), i.e 8-times and 3-times better than MMP-12. PJ-8, the best MMP-12 substrate in group I, was only 5-times better for MMP-12 than for MMP-13. The situation was similar for groups II and III substrates, all of which, except PP-6 and PJ-9, were better for MMP-12. PP-6 and PJ-9 had slightly higher or similar $k_{\text {cat }} / K_{\mathrm{m}}$ values with MMP-2 and MMP-9. Once again, MMP-13 catalysed the cleavage of some group II and III substrates more actively than did MMP-12. For example, the MMP-12/MMP-13 selectivity ratio for PJ-10 was 0.4 , that for PJ-7 was 0.34 and that for PJ-9 was 0.25 . Most group IV substrates, whose sequences span MMP-12 cleavage sites in natural substrates and do not contain the Pro-X-X- $\downarrow-X_{\mathrm{HY}}$ motif, were poorly hydrolyzed by MMP-2, -7 and -9 . However, MMP-13 cleaved these substrates more efficiently than did MMP-2, -7 and -9 with a selectivity ratio of 0.2 for PP-15. PP-16, whose sequence is derived from that of one of the two sites in CXCL5 cleaved by human MMP-12, appeared to be the most selective of all the 21 substrates that we have designed. It was hydrolyzed by h-FL-MMP-12 with a $k_{\text {cat }} / K_{\mathrm{m}}$ of $140 \mathrm{mM}^{-1} \mathrm{~s}^{-1}$, a value similar to that for Mca-PLGLEEA-Dpa-NH $\mathrm{N}_{2}$ (Devel et al., 2006). But, unlike this later substrate, it was very poorly hydrolyzed by the other MMPs tested, with a selectivity ratio greater than 70, i.e reaching nearly two orders of magnitude. To confirm our finding that PP-16 is a selective substrate for human MMP-12, we have extended our study to MMP-1, $-3,-8$ and -14 . As expected, they were all able to cleave PJ-9 with $k_{\text {cat }} / K_{\mathrm{m}}$ values in the same range as those determined for MMP-2, -7, -9 and -13 but they did not cleave significantly PP-16 substrates $\left(k_{\text {cat }} / K_{\mathrm{m}}<2 \mathrm{mM}^{-1} \mathrm{~s}^{-1}\right)$.

Altogether our results suggest that PP-16 could make an appropriate substrate for selectively evaluating MMP-12 proteolytic activity in biological fluids containing other MMPs.

\section{Modeling peptide substrate interactions with MMP-12}

It is not clear just how substrates interact with residues of the MMP-12 active site and how these residues contribute to substrate specificity because no X-ray structure of MMP-12 complexed with uncleaved peptide substrates is available. However, the 3D structures of MMP-12 complexed with inhibitors or adducts resulting from cleavage of substrates provide structural information on the way the residues on either the $\mathrm{P}$ side or the $\mathrm{P}^{\prime}$ side of MMP-12 
substrates interact with the enzyme. Based on the MMP-12 / Ile-Ala-Glu complex, where Ile, Ala and Glu represent P1', P2' and P3' residues respectively, we have positioned the peptide RNALA $\downarrow$ VERTAS of the selective PP-16 substrate into the MMP-12 catalytic cleft and submitted the complex to FlexPepDock without any constraints during the docking procedure. The peptide substrate fits snugly into the crevice running across the active site of MMP-12 and forms numerous contacts, including hydrogen bonds with enzyme residues (Figure 2). The side-chain of the P1' residue Val penetrates into the deep S1' pocket without filling it completely, suggesting that a longer side-chain like that of leucine or possibly norleucine would be highly favorable at that position. A striking feature of the docked peptide is that the Leu at P2 is sandwiched between the enzyme residues His 172 and Ile 180 to form hydrophobic contacts with contact areas as large as $35.5 \AA^{2}$ and $46.5 \AA^{2}$. Another interesting feature revealed by the peptide docking is that the Arg at P5 interacts strongly with enzyme Phe 171 (contact area $57.7 \AA^{2}$ ) and Phe 185 (contact area $35.5 \AA^{2}$ ), probably through pi-cation interactions. This favorable binding of both Leu P2 and Arg P5 suggests that these two PP-16 residues make major contributions to substrate binding and could be anchor points driving binding to ensure that cleavage occurs at the Ala-Val bond rather than at the bond with Leu at P'1. These docking results all converged on the same binding features when other substrates containing Arg at P4, Pro at P3 and Leu at P2 (e.g PJ-8 substrate) were included in the docking procedure (data not shown). The conformation of the Pro at P3 in PJ-8 introduced a bend in the peptide that enabled the side-chain at $\mathrm{P} 4$ to interact with the enzyme residues Phe 171 and Phe 185. Our results suggest that both Phe residues in MMP-12 are essential for driving substrate binding mode. These results of our docking experiments were unexpected but such an Arg-Phe interaction between the Arg at P4 of a substrate complexed to MMP-14, a related enzyme that also favors Arg at that position, has been previously reported (Kridel et al., 2002). While hydrophobic interactions make a major contribution to peptide binding to the MMP-12 active site, the substrate residues Asn 2, Val 6, Glu 7 and $\operatorname{Arg} 8$ formed a total of seven hydrogen bonds (Fig. 2C). We detected no true electrostatic interactions involving charged residues of the RNALAVERTAS peptide because no charged residues are close enough to the active site crevice where peptide substrates bind. Our docking experiments revealed that the residues of the so-called S-loop (Ala 167-Leu 181) and specificity loop (Ala 234-Asp 244) of MMP-12 are involved in a significant proportion of the peptide-enzyme interactions. These two loops differ from one MMP to another and are involved in substrate specificity. Our results reinforce the role of these two loops in determining specificity and selectivity for substrate binding. 


\section{Discussion}

The catalytic clefts of all MMPs have very similar structural features. They all contain a zinc ion and a glutamic acid residue involved in catalysis, plus a deep S1' pocket that can accommodate long hydrophobic side-chains, frequently a leucine, at substrate position P1'. Proline is often the preferred residue at substrate position P3 and the Pro-X-X- $\downarrow-X_{H Y}$ motif has been frequently used to generate very good substrates for a wide range of MMPs. These results indicate that the substrate recognition profiles of MMPs overlap considerably. However, in some cases, it has been possible to identify discriminatory sequences that provide quite a high degree of selectivity for substrates of some individual MMPs (Chen et al., 2002, 2003; Deng et al., 2000; Kridel et al., 2001).

We examined sequences spanning the cleavage sites in all the known substrates of MMP-12, comprising both globular and structural proteins, in order to identify sequences useful for designing new, selective substrates for the enzyme. We identified the residue most frequently found at each position from $\mathrm{P} 4$ to $\mathrm{P} 4$ ' on both sides of the cleavage site so as to generate a sequence preferentially recognized by MMP-12. This 'amino acid consensus' strategy does not take into account any interdependence of subsites for accommodating substrate residues, but this seems to be less important for MMPs than for other enzymes, such as serine proteases. Collagen and elastin, two natural ECM substrates of MMP-12 and other MMPs, contain high proportions of glycine and proline (or hydroxyproline) residues and these are also frequently found at some positions in the cleavage sites. For example, Gly is the most frequent amino acid at the P4, P1 and P3' sites of types I and III skin collagens cleaved by MMP-12, while Pro/HyP predominates at P3 and Leu is the preferred amino acid at P1' (Taddese et al., 2010). A consensus sequence derived from these ECM substrates would have a low complexity content of amino acid and would probably be cleaved by many other MMPs. We designed a lead substrate (PJ-1) using only those preferred amino acids around the cleavage sites in soluble, globular proteins that were recognized by MMP-12 and then modified it by amino acid substitutions to generate substrates with better specificity and selectivity for MMP-12. All but one of the PJ-1-derived substrates were hydrolyzed, more or less efficiently, by MMP-2, -7, -9 and -13 . The exception, PJ-8, appeared to be the substrate most selective for MMP-12, perhaps because all the others contain the motif Pro-X-X- $\downarrow-X_{H Y}$ (where $\mathrm{X}_{\mathrm{HY}}$ is Leu in our study) that occurs frequently in synthetic substrates for MMPs. PP-23, which lacks a Pro at P3, was a poor substrates for MMP-12 and the other MMPs 
tested, providing further evidence that a Pro at P3 is important for substrate binding and/or the correct positioning of the substrate for efficient hydrolysis. The cleavage site in PP-23 was also shifted with a second, minor cleavage $(\approx 5 \%)$ at the Trp-Arg bond, in addition to cleavage at the Ala-Leu bond. However, the catalytic efficiency of MMP-12 against this substrate was significantly decreased. The most suitable MMP-12 substrates, like PP-19 and PP-2, had an Arg at P4 and were more readily cleaved than those that did not (PP-20 and PP-2b). But other MMPs also cleaved these P4 Arg-containing substrates more readily and replacing this Arg with Glu in PP-21 had no deleterious effects on its hydrolysis by MMP-12. Hence one can deduce that introducing Arg at P4 of substrates is not sufficient to gain selectivity for MMP-12 hydrolysis. Surprisingly, drastic amino acid substitutions at primed positions (P2', P3') of our substrates, such as Trp-->Arg, Trp-->Glu and Arg-->Glu, had no significant effect on substrate hydrolysis. This may be because these amino acid side-chains are bound differently at the substrate-enzyme interface or because these residues make a smaller contribution to substrate binding energy than does P1', where Leu interacts very favorably with the deep S1' pocket as previously reported and probably provides most of the binding energy (Gronski, Martin et al. 1997).

The information inferred from analysis of sites in ECM proteins (group III substrates) cleaved by MMP-12 did not help generate efficient and/or selective substrates for MMP-12. Short side-chains like those of Ala and Gly are unlikely to provide enough specific interactions between substrate residues and a given MMP active site. In contrast, group IV substrates derived from proteins reported to be physiological substrates of MMP-12, were generally poorer substrates for other MMPs compared to MMP-12, than were the groups I, II and III substrates. The substrate PP-16, with the peptide sequence RNALAVERTAS derived from the chemokine CXCL5, was the most selective for MMP-12 of all the 21 substrates tested. Although the $k_{\text {cat }} / K_{\mathrm{m}}$ for its hydrolysis by human MMP-12 does not exceed the $10^{5} \mathrm{M}^{-1} \mathrm{~s}^{-1}$ range, it is similar to that for the sequence PLGLEEA (PP-2b) and to that for Mca-PLGLEEA-Dpa-NH $\mathrm{N}_{2}$ (Devel et al., 2006). But unlike Mca-PLGLEEA-Dpa-NH $\mathrm{NH}_{2}$ wich is widely used as a commercial substrate to determine MMP-12 activity but is clearly not very selective for MMP-12, PP-16 substrate proved to be a much better substrate since it was very poorly or not hydrolyzed, by other MMPs including MMP-1, -2, -3, -7, -8, -9, -13 and -14. Surprisingly, substrate PP-16 does not have a proline at position P3, although this residue is favoured in substrates that are common to most MMPs (Ratnikov et al., 2014). This implies that substrates that are selective for MMP-12, and possibly for other MMPs, may be obtained 
using sequences without a proline at P3 or other positions. Similar results were obtained for MMP-14 substrates; replacing the Pro at P3 in an unselective substrate with another residue gave a selective one (Kridel et al., 2002). This study also showed that the Arg at P4 as important for both efficient hydrolysis and selectivity. We also found that an arginine at P4 tended to be highly favorable in MMP-12 substrates.

MMP-13 cleaved most of our substrates, except PP-16, much more actively than other MMPs, including MMP-12, although this was not the major goal of our study. Others have reported similar findings, especially with the common MMP substrate FS-6 (Mca-KPLGL-Dpa-ARNH2), which is a ten times better substrate for MMP-13 (Neumann et al., 2004) than for MMP-12 (Palmier et al., 2007); the activities of MMP-2, MMP-7 and MMP-9 with this substrate are somewhere between the two (Neumann et al., 2004). This could be because MMP-13 has a higher intrinsic activity than other MMPs. Some serine protease families behave similarly. It could also be due to the peptide sequences of the synthetic substrates.

Full-length MMP-12, either human or murine, is far more active than the catalytic domain alone, although the latter may be active enough to digest protease-resistant substrates such as elastin (Shapiro et al., 1993) and collagen V (Fu et al., 2001). This seems to be a unique situation among MMPs, which usually require one or more exosites, such as the fibronectinlike inserts of MMP-2 and MMP-9 for binding to elastin or collagen. It is not clear, however, how full-length MMP-12 can catalyse the hydrolysis of small synthetic substrates more efficiently than the catalytic domain alone. This may be due to the high flexibility of the interdomain region in MMP-12, i.e between the catalytic domain and the hemopexin domain, resulting in high conformational freedom with respect to each other (Bertini et al., 2008). Consequently this may then influence substrate binding in some way so that the transition state is stabilized and so increase substrate turn-over $\left(k_{\mathrm{cat}}\right)$ in the presence of the hemopexinlike domain. MMP-12, unlike other MMPs, tends to be processed so that its C-ter hemopexin domain is removed auto-catalytically (Bertini et al., 2008), suggesting that the $22 \mathrm{kDa}$ catalytic domain is the active form of MMP-12 in vivo (Shapiro et al., 1993). We have examined the molecular forms of human and murine MMP-12 following the activation of full-length proforms according to the supplier's protocols. Our SDS-PAGE studies (Figure S1) indicate that most of the human and murine MMP-12s mature to their full-length forms, although there were also minor protein bands of about $20 \mathrm{kDa}$, probably corresponding to the catalytic domain. Thus there are really significant differences between the catalytic activities of FL-MMP-12 and its catalytic domain, both active site-titrated before determining 
kinetic constants. Using self-assembling triple helical peptide substrates as mimics of collagens, Bhaskaran et al. (2008) showed that the C-terminal hemopexin-like domain of MMP-12, and even that of MMP-9, clearly decrease $K_{\mathrm{m}}$ and consequently enhance the $k_{\text {cat }} / K_{\mathrm{m}}$ values for hydrolysis of these 15-mer substrates. Our results also show that the hemopexin domain influenced the hydrolysis of our peptide substrates, although they are shorter and non-helical. Perhaps there are long-range communication networks between distal structural elements and the catalytic site. Further studies are now required to determine whether this difference in the catalytic potential of the two forms of MMP-12 is a way of regulating the activity of this enzyme in vivo.

It is not at all clear why the catalytic activity of mouse MMP-12 is lower than that of human MMP-12 when assayed with our substrates, which were initially designed for human MMP-12. The catalytic domain and full-length murine MMP-12 are unlikely to both be inactive; our SDS-PAGE and zymography data indicate that they cleaved human $\alpha 1-P I$ and elastin. As expected, the catalytic domain acted more slowly than full-length MMP-12 (data not shown). On the other hand, the substrate recommended for determining murine MMP-12 activity by its manufacturers, Mca-KPLGL-Dpa-AR, is somewhat different from the peptide Mca-PLGLEEA-Dpa- $\mathrm{NH}_{2}$ usually recommended for measuring human MMP-12 activity. This suggests that sequences deduced from analysis of the cleavage sites in protein substrates of human MMP-12 are not recognized by murine MMP-12. We previously observed a similar situation whereby fluorogenic substrates developed for human neutrophil elastase are not hydrolyzed by its murine orthologue due to subtle amino acid differences in the active site subsites (Kalupov et al., 2009), although the sequences of the two proteases are quite similar. The sequences of the catalytic domains of human and murine MMP-12 are 65\% identical, so $35 \%$ of residues differ. Mapping the amino acid differences onto the $3 \mathrm{D}$ structure of MMP-12 showed that many of them (data not shown) lie in the so-called S-loop and the specificity loop; two loops that are involved in substrate binding and that differ from one MMP to another. This may provide a structural explanation for why substrates designed for human MMP-12 are poorly recognized by murine MMP-12.

The differing substrate specificities of human and mouse MMP-12s raise the question of the true role of MMP-12 in protease-driven lung diseases, especially in COPD where MMP-12 is thought to play a key pathogenic role. This assumption was largely based on the finding that MMP-12-deficient mice are, unlike normal mice, fully protected from tobacco smoke-induced emphysema (Hautamaki et al., 1997). But the relevance of MMP-12 in human pathogenesis 


\section{Substrate specificity of MMP-12}

remains controversial because some studies have demonstrated that the increased elastinolytic activity in the lungs of people suffering from emphysema is not due to an increase in MMP-12 (Finlay et al., 1997), but to increases in other MMPs and neutrophil elastase. Others have suggested that the predominant macrophage protease in mice is MMP-12, while human macrophages have a wider spectrum of MMPs (Shapiro, 2003). This, together with our results showing that human and murine MMP-12s may have different specificity and consequently different protein substrates in vivo, emphasises the need for caution in interpreting the results obtained from mouse model of COPD (Shapiro, 2000).

The PP-16 FRET substrate based on the peptide sequence RNALAVERTAS may be useful for selectively measuring MMP-12 activity in samples of human origin because the concentration of MMP-12 in biological fluids is much lower than those of to other MMPs like MMP-2 and MMP-9. While our results suggest that it may provide a valuable template for developing activity-based probes for visualizing MMP-12 activity in vivo, further studies are needed to confirm its selectivity for MMP-12.

\section{Materials and methods}

\section{Materials}

Full-length human MMP-1, $-2,-3,-7,-8,-9,-13,-14$ and -12 and full-length murine MMP-12 were purchased from R\&D Systems Europe (Lille, France). Non-tagged catalytic domain of human MMP-12 was bought from Sino Biological Inc (Interchim, Montluçon, France). All other reagents were of analytical grade.

\section{Synthesis and purification of catalytic domain of MMP-12s}

The catalytic domain of human MMP-12 (h-CAT-MMP-12) was amplified by PCR using the

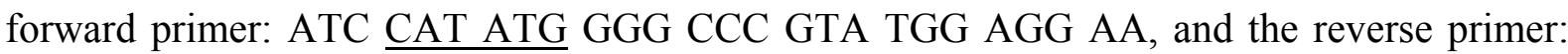
ATT GGA TCC TCA GTG GTG GTG GTG GTG GTG TCC ATA CAG GGA CTG AAT G containing a 6-His tag sequence for further purification (Eurofins, France). The triplets corresponding to Nde1 and BamH1 restriction sites are underlined. We used MMP-12 cDNA cloned into pCR4-TOPO (Open BioSystems, USA) as a template for PCR amplification with Taq/Pwo polymerase (Roche, Germany). The resulting amplified fragments were digested and cloned into the pET11a vector (Merck Millipore). The cDNA sequence was checked for the 


\section{Substrate specificity of MMP-12}

absence of mutations by nucleotide sequencing (Fasteris, Switzerland). The pET11a/h-CATMMP-12 plasmid was then integrated into E. coli BL21 (DE3) competent cells (Novagen) by the heat-shock method. Positive clones were grown in LB medium and ampicillin at $37^{\circ} \mathrm{C}$.

High level expression of h-CAT-MMP-12 was induced by addition of IPTG to cultures once their $\mathrm{OD}_{600}$ reached 0.6 . The cells were harvested by centrifugation 4 hours after induction and lysed by three heat-shock cycles $\left(37^{\circ} \mathrm{C}, 10 \mathrm{~min}\right.$ and $\left.-80^{\circ} \mathrm{C}, 10 \mathrm{~min}\right)$, followed by incubation with lysozyme ( $2 \mathrm{mg} / \mathrm{g}$ of pellet) for $10 \mathrm{~min}$ with gentle shaking. The pellet was collected by centrifugation ( $9500 \mathrm{rpm}, 4^{\circ} \mathrm{C}, 30 \mathrm{~min}$ ) and suspended in $20 \mathrm{mM}$ Tris- $\mathrm{HCl}, \mathrm{pH}$ 8.0. Inclusion bodies were isolated by centrifuging this suspension at $9500 \mathrm{rpm}$ for $30 \mathrm{~min}$ and dissolved in $50 \mathrm{mM}$ HEPES (N-(2-hydroxyethyl)-piperazine-N'-2-ethanesulfonic acid) buffer pH 7.5 containing $150 \mathrm{mM} \mathrm{NaCl}, 5 \mathrm{mM} \mathrm{CaCl}_{2}, 0.05 \%$ Brij35, 7M GuHCl, $10 \mathrm{mM}$ imidazole at room temperature. Samples containing MMP-12 were applied to a His-Trap affinity chromatography column connected to an ÄKTA Purifier chromatographic system (GE Healthcare, Vélizy Villacoublay, France) and the column washed extensively with the same buffer. Bound His-tagged MMP-12 was eluted with a gradient of imidazole (10-500 mM). h-CAT-MMP-12 was then renatured by buffer exchange against HBNC buffer using a PD10 desalting column (GE Healthcare, Vélizy Villacoublay, France).

The identity of h-CAT-MMP-12 was confirmed by polyacrylamide gel electrophoresis, western blotting using a polyclonal anti-MMP-12 antibody (Abcam, Cambridge, UK), and sequencing the N-terminal amino acids. The molar concentration of active h-CAT-MMP-12 was determined by active site titration using the MMP inhibitor GM 6001 (Merck Millipore) and the Sensolyte ${ }^{\circledR} 490$ MMP fluorogenic substrate (Anaspec, Eurogentec).

The catalytic domain of murine MMP-12 was expressed using the same protocol starting from the cDNA coding mouse MMP-12 cloned in pDONR vector (Gencopeia, Tebu-bio, Le Perray-en-Yvelines, France) except that inclusion bodies were dissolved in $50 \mathrm{mM}$ Tris-HCl buffer, pH 7.5 containing $150 \mathrm{mM} \mathrm{NaCl}, 10 \mathrm{mM} \mathrm{CaCl}_{2}, 0.05 \%$ Brij 35, 7M guanidine hydrochloride and $10 \mathrm{mM}$ imidazole. Enzyme activity was measured in $50 \mathrm{mM}$ Tris- $\mathrm{HCl}$ buffer, pH 8.0 containing $150 \mathrm{mM} \mathrm{NaCl}, 10 \mathrm{mM} \mathrm{CaCl}_{2}$ and $0.05 \%$ Brij 35. Active site titration was performed using the same procedure as that used for human MMP-12 using PJ-1 substrate. 


\section{Design and synthesis of fluorogenic substrates}

The nomenclature of Schechter and Berger (1967) is used for individual amino acid residues (P1, P2, etc.) of substrates and enzyme subsites (S1, S2 etc.). We analysed the frequencies of all 20 amino acids in the P4 to P4' region of known MMP-12 cleavage sites in various protein substrates to identify peptide sequences that could be used to design selective substrates for human MMP-12 that were not cleaved by other MMPs The cleavage sites were obtained from the MEROPS database at http://merops.sanger.ac.uk/ (Rawlings et al., 2014) and/or from the literature (Table S1, Supplementary Information). The consensus sequence RPLALWRS deduced from the cleavage sites of soluble substrates was used as a lead sequence to synthesize a series of fluorogenic Abz-EDDnp substrates with Abz (ortho-aminobenzoic acid) as fluorescent group and EDDnp N-(2,4-dinitrophenyl)ethylenediamine as quencher group. We also synthesized a series of substrates derived from the peptide sequence PLGLEEA because this sequence is readily cleaved by most MMPs and is partially selective for human MMP-12 (Devel et al., 2006). Lastly, we used peptide sequences spanning the known sites in human and mouse $\alpha 1-\mathrm{PI}$, human CXCL1 and mouse CXCL5 that are cleaved quite efficiently by MMP-12.

Abz-peptidyl-EDDnp fluorogenic substrates were synthesized by solid-phase Fmoc (N-(9-fluorenyl)methoxycarbonyl) methodology using a multiple automated peptide synthesizer (PSSM-8, Shimadzu Co.) as previously described (Chagas et al., 1991; Hirata et al., 1994). The synthesis strategy resulted in glutamine being the C-terminal residue in all these substrates (Hirata et al., 1994). Substrate purity was checked by matrix-assisted laser desorption ionization-time of flight mass spectrometry (MALDI-TOF; Micromass, TofSpecE) and by reverse-phase chromatography on a C18 column eluted at $3 \mathrm{ml} / \mathrm{min}$ with a $25-\mathrm{min}$ linear gradient of acetonitrile (0-60\%) in $0.075 \%$ trifluoroacetic acid. Some peptide substrates were also synthesized ( $>95 \%$ purity) by ProteoGenix SAS (Schiltigheim, France); their purity was checked by standard MALDI-TOF analysis. Stock solutions of substrate (2-5 mM) were prepared in N,N-dimethylformamide and diluted with activity buffer. The concentrations of the Abz-peptidyl-EDDnp substrate were determined by measuring the absorbance at $365 \mathrm{~nm}$, using $\varepsilon_{365 \mathrm{~nm}}=17,300 \mathrm{M}-1 \mathrm{~cm}-1$ for EDDnp. 


\section{Enzyme assays and kinetic studies}

Assays were carried out at $30^{\circ} \mathrm{C}$ in $50 \mathrm{mM}$ HEPES buffer, pH 7.5, $150 \mathrm{mM} \mathrm{NaCl}, 5 \mathrm{mM}$ $\mathrm{CaCl} 2,0.05 \%$ Brij35. Hydrolysis of the Abz-peptidyl-EDDnp substrates was followed by measuring the fluorescence at $\lambda_{\mathrm{ex}}=320 \mathrm{~nm}$ and $\lambda_{\mathrm{em}}=420 \mathrm{~nm}$ in a Varian Cary Eclipse spectrofluorometer. Specificity constants $\left(k_{\mathrm{cat}} / K_{\mathrm{m}}\right)$ were determined under first-order conditions, using a substrate concentration $(5 \mu \mathrm{M})$ far below the $K_{\mathrm{m}}$ and a final enzyme concentration of $10 \mathrm{nM}$. Under these conditions, the Michaelis-Menten equation is reduced to: $\mathrm{v}=k_{\mathrm{obs}} . \mathrm{S}$, where $k_{\mathrm{obs}}=V_{\mathrm{m}} / K_{\mathrm{m}}$. Integrating this equation over time gives $\ln [\mathrm{S}]=-k_{\mathrm{obs}} . \mathrm{t}+\ln [\mathrm{S}]_{0}$ with $[\mathrm{S}]_{0}$ and $[\mathrm{S}]$, being the substrate concentrations at time 0 and time $\mathrm{t}$, respectively. Since $V_{\mathrm{m}}=k_{\text {cat }}$ [E]t, where [E]t is the final enzyme concentration, dividing $k_{\mathrm{obs}}$ by [E]t gave the $k_{\mathrm{cat}} / K_{\mathrm{m}}$ ratio. The $\mathrm{k}_{\mathrm{obs}}$ for the first-order substrate hydrolysis was calculated by fitting experimental data to the first-order law using GraphPad Prism 5 software (GraphPad Software, La Jolla, CA, USA).

Individual $K_{\mathrm{m}}$ and $V_{\mathrm{m}}$ values for the hydrolysis of Abz-peptidyl-EDDnp substrates by MMP12 were determined using 8-10 substrate concentrations $(0.2-20 \mu \mathrm{M})$; the final concentration of MMP-12 was always $10 \mathrm{nM}$. Experimental data were fitted to the hyperbolic MichaelisMenten rate equation using GraphPad Prism 5 software. $k_{\text {cat }}$ values were obtained from $V_{\mathrm{m}} /[\mathrm{E}] \mathrm{t}$.

\section{Chromatographic procedures and identification of cleavage sites}

Fluorogenic substrates $\left(60 \mu \mathrm{M}\right.$ final) were incubated with MMPs at $30^{\circ} \mathrm{C}$ in their respective buffers. Reactions were blocked by adding $100 \mu 1$ aqueous TFA (0.075\%). Peptide fragments were separated by reverse phase chromatography on a C18 column $(2.1 \mathrm{~mm} \times 30 \mathrm{~mm}$, Merck) connected to an Agilent 12 series HPLC (high performance liquid chromatography) system pump at a flow rate of $3 \mathrm{ml} / \mathrm{min}$, with a linear $(0-60 \%, \mathrm{v} / \mathrm{v})$ gradient of acetonitrile in $0.075 \%$ TFA over $25 \mathrm{~min}$. Eluted peaks were monitored simultaneously at $220 \mathrm{~nm}$ (peptide bond), $320 \mathrm{~nm}$ (Abz group) and $360 \mathrm{~nm}$ (EDDnp group). Selected peptide fragments were analysed by Matrix Assisted Laser Desorption Ionisation-Time of Flight (MALDI-TOF) or ElectroSpray Ionisation - Ion Trap (ESI-IT) mass spectrometry to identify cleavage sites. MALDI-TOF-MS spectra were obtained on an UltraFlex I mass spectrometer (Bruker Daltonics). Samples were diluted ten-fold in a saturated solution of 4-hydroxy- $\alpha$-cyanocinnamic acid in $33.3 \%$ acetonitrile, $66.6 \%$ water and $0.1 \%$ trifluoroacetic acid. Matrix- 
sample solutions were spotted onto a gold-plated sample probe using the ultrathin layer method (Cadene et al., 2000; Gabant et al., 2008). Spectra were acquired in the reflectron positive ion mode (1000 laser shots) over the range 500 to $3500 \mathrm{~m} / \mathrm{z}$. The pepmix I calibration kit (Bruker) was used for calibration using the near-neighbor spot strategy. MALDI-TOF-MS spectra were processed using FlexAnalysis 3.3 software from Bruker Daltonics. ESI-IT-MS spectra were recorded on a HCTultra PTM Discovery System mass spectrometer (Bruker Daltonics) equipped with an electrospray ion source. Acquisitions were carried out in positive ionization mode and at standard/enhanced resolution $(8100 \mathrm{~m} / \mathrm{z}$ per second $)$. ESI-IT-MS spectra were processed and charge deconvoluted using DataAnalysis 3.1 software (Bruker Daltonics). Cleavage peptides were assigned using Paws version 8.5.0.3 (ProteoMetrics, New York, USA).

\section{Docking studies of peptide substrates}

We used docking studies to help visualize the interaction of substrates with residues of the MMP-12 active site. We first built a model of MMP-12 complexed with the peptide sequence RNALAVERTAS (substrate PP-16) by superimposing the X-ray structure of the catalytic domain of MMP-12 from the 1JK3 PDB (Protein Data Bank) file on the MMP-12 / Ile-AlaGly peptide complex (2OXW PDB file). MMP-12 forms an adduct with this peptide moiety following cleavage of the collagen-derived peptide Pro-Gln-Gly-Ile-Ala-Gly at the Gly-Ile bond (Bertini et al., 2006). This reveals the interactions between substrate residues P1'-P2'-P3' with MMP-12 S' subsites. The peptide sequence of substrate PP-16 was constructed in an extended conformation using Pymol software and positioned in the MMP-12 active site by superimposing the Val-Glu-Arg backbones of PP-16 on Ile-Ala-Gly residues of the 2OXW structure. We used this procedure because the MMP-12 structure from the 2OXW PDB file has the Phe171Asp mutation (frequently introduced into recombinant MMP-12 because it stabilises the enzyme), while that of the JK3 file does not. The complex formed between the catalytic domain of MMP-12 and the undocked PP-16 substrate was submitted to the FlexPepDock (http://flexpepdock.furmanlab.cs.huji.ac.il) software, a high-resolution docking tool of the Rosetta suite that allows full flexibility of both peptide residues and side-chains of the receptor active site to be taken into account during the docking procedure (London et al., 2011). The top five models of peptide interactions with MMP-12, sorted by their Rosetta score, were examined with Pymol software (Schrödinger LLC, New York). 


\section{Acknowledgements}

Mass spectrometry analyses were performed by the «Plateforme de Spectrométrie de Masse et Protéomique» of the Center for Molecular Biophysics in Orléans, France. N-terminal amino acid sequence analyses were performed by the «Plateforme Protéomique Pissaro» at the University of Rouen, France. ASL was supported by a PhD fellowship from the Conseil Régional Centre-Val de Loire. RG was awarded with a post-doctoral fellowship from the Conseil Régional Centre-Val de Loire and the programme Investissement d'Avenir Grant Agreement Labex Mab'Improve (ANR-10-LABX-53). The English text was edited by Dr. Owen Parkes. 


\section{References}

Banda, M. J., Clark, E. J., Sinha, S., and Travis, J. (1987). Interaction of mouse macrophage elastase with native and oxidized human $\alpha 1$-proteinase inhibitor. J. Clin. Invest. 79, 1314-1317.

Banda, M. J., Clark, E. J., and Werb, Z. (1980). Limited proteolysis by macrophage elastase inactivates human $\alpha 1$-proteinase inhibitor. J. Exp. Med. 152, 1563-1570.

Bertini, I., Calderone, V., Fragai, M., Jaiswal, R., Luchinat, C., Melikian, M., Mylonas, E., and Svergun, D. I. (2008). Evidence of reciprocal reorientation of the catalytic and hemopexin-like domains of full-length MMP-12. J. Am. Chem. Soc. 130, 7011-7021.

Bertini, I., Calderone, V., Fragai, M., Luchinat, C., Maletta, M., and Yeo, K. J. (2006). Snapshots of the reaction mechanism of matrix metalloproteinases. Angew Chem. Int. Ed. 45, 7952-7955.

Bhaskaran, R., Palmier, M. O., Lauer-Fields, J. L., Fields, G. B., and Van Doren, S. R. (2008). MMP-12 catalytic domain recognizes triple helical peptide models of collagen V with exosites and high activity. J. Biol. Chem. 283, 21779-21788.

Cadene, M., and Chait, B. T. (2000). A robust, detergent-friendly method for mass spectrometric analysis of integral membrane proteins. Anal. Chem. 72, 5655-5658.

Chagas, J. R., Juliano, L., and Prado, E. S. (1991). Intramolecularly quenched fluorogenic tetrapeptide substrates for tissue and plasma kallikreins. Anal. Biochem. 192, 419-425.

Chen, E. I., Kridel, S. J., Howard, E. W., Li, W., Godzik, A., and Smith, J. W. (2002). A unique substrate recognition profile for matrix metalloproteinase-2. J. Biol. Chem. 277, 4485-4491.

Chen, E. I., Li, W., Godzik, A., Howard, E. W., and Smith, J. W. (2003). A residue in the S2 subsite controls substrate selectivity of matrix metalloproteinase-2 and matrix metalloproteinase-9. J. Biol. Chem. 278, 17158-17163.

Cobos-Correa, A., Trojanek, J. B., Diemer, S., Mall, M. A., and Schultz, C. (2009). Membrane-bound FRET probe visualizes MMP12 activity in pulmonary inflammation. Nat. Chem. Biol. 5, 628-630.

Curci, J. A., Liao, S., Huffman, M. D., Shapiro, S. D., and Thompson, R. W. (1998). Expression and localization of macrophage elastase (matrix metalloproteinase-12) in abdominal aortic aneurysms. J. Clin. Invest. 102, 1900-1910.

Dean, R. A., Cox, J. H., Bellac, C. L., Doucet, A., Starr, A. E., and Overall, C. M. (2008). Macrophage-specific metalloelastase (MMP-12) truncates and inactivates ELR $^{+} \mathrm{CXC}$ chemokines and generates CCL2, $-7,-8$, and -13 antagonists: potential role of the macrophage in terminating polymorphonuclear leukocyte influx. Blood 112, 3455-3464.

Demedts, I. K., Morel-Montero, A., Lebecque, S., Pacheco, Y., Cataldo, D., Joos, G. F., Pauwels, R. A., and Brusselle, G. G. (2006). Elevated MMP-12 protein levels in induced sputum from patients with COPD. Thorax 61, 196-201.

Deng, S. J., Bickett, D. M., Mitchell, J. L., Lambert, M. H., Blackburn, R. K., Carter, H. L., 3rd, Neugebauer, J., Pahel, G., Weiner, M. P., and Moss, M. L. (2000). Substrate specificity of human collagenase 3 assessed using a phage-displayed peptide library. J. Biol. Chem. 275, 31422-31427. 
Devel, L., Rogakos, V., David, A., Makaritis, A., Beau, F., Cuniasse, P., Yiotakis, A., and Dive, V. (2006). Development of selective inhibitors and substrate of matrix metalloproteinase-12. J. Biol. Chem. 281, 11152-11160.

Finlay, G. A., O'Driscoll, L. R., Russell, K. J., D'Arcy, E. M., Masterson, J. B., FitzGerald, M. X., and O'Connor, C. M. (1997). Matrix metalloproteinase expression and production by alveolar macrophages in emphysema. Am. J. Respir. Crit. Care Med. 156, 240-247.

Fu, J. Y., Lyga, A., Shi, H., Blue, M. L., Dixon, B., and Chen, D. (2001). Cloning, expression, purification, and characterization of rat MMP-12. Protein Expr. Purif. 21, 268-274.

Gabant, G., and Cadene, M. (2008). Mass spectrometry of full-length integral membrane proteins to define functionally relevant structural features. Methods 46, 54-61.

Gronski, T. J., Jr., Martin, R. L., Kobayashi, D. K., Walsh, B. C., Holman, M. C., Huber, M., Van Wart, H. E., and Shapiro, S. D. (1997). Hydrolysis of a broad spectrum of extracellular matrix proteins by human macrophage elastase. J. Biol. Chem. 272, 1218912194.

Haq, I., Lowrey, G. E., Kalsheker, N., and Johnson, S. R. (2011). Matrix metalloproteinase-12 (MMP-12) SNP affects MMP activity, lung macrophage infiltration and protects against emphysema in COPD. Thorax 66, 970-976.

Hautamaki, R. D., Kobayashi, D. K., Senior, R. M., and Shapiro, S. D. (1997). Requirement for macrophage elastase for cigarette smoke-induced emphysema in mice. Science 277, 2002-2004.

Heinz, A., Jung, M. C., Duca, L., Sippl, W., Taddese, S., Ihling, C., Rusciani, A., Jahreis, G., Weiss, A. S., Neubert, R. H., and Schmelzer, C. E. (2010). Degradation of tropoelastin by matrix metalloproteinases - cleavage site specificities and release of matrikines. FEBS J. 277, 1939-1956.

Hirata, I. Y. , Cezari, M. H. S., Nakaie, C. R., Boschcov, P., Ito, A. S. , Juliano, M. , and Juliano, L. (1994). Internally quenched fluorogenic protease substrates: solid-phase synthesis and fluorescent spectroscopy of peptides containing ortho-aminobenzoyldinitrophenyl groups as donor-acceptor pairs. Lett. Pept. Sci. 1, 299-308.

Houghton, A. M., Quintero, P. A., Perkins, D. L., Kobayashi, D. K., Kelley, D. G., Marconcini, L. A., Mecham, R. P., Senior, R. M., and Shapiro, S. D. (2006). Elastin fragments drive disease progression in a murine model of emphysema. J. Clin. Invest. $116,753-759$.

Hunninghake, G. M., Cho, M. H., Tesfaigzi, Y., Soto-Quiros, M. E., Avila, L., Lasky-Su, J., Stidley, C., Melen, E., Soderhall, C., Hallberg, J., Kull, I., Kere, J., Svartengren, M., Pershagen, G., Wickman, M., Lange, C., Demeo, D. L., Hersh, C. P., Klanderman, B. J., Raby, B. A., Sparrow, D., Shapiro, S. D., Silverman, E. K., Litonjua, A. A., Weiss, S. T., and Celedon, J. C. (2009). MMP12, lung function, and COPD in high-risk populations. N. Engl. J. Med. 361, 2599-2608.

Kalupov, T., Brillard-Bourdet, M., Dade, S., Serrano, H., Wartelle, J., Guyot, N., Juliano, L., Moreau, T., Belaaouaj, A., and Gauthier, F. (2009). Structural characterization of mouse neutrophil serine proteases and identification of their substrate specificities: relevance to mouse models of human inflammatory diseases. J. Biol. Chem. 284, 34084-34091.

Kaynar, M., and Shapiro, S.D. (2012). Matrix Metallopeptidase-12/Macrophage elastase. In: Handbook of Proteolytic Enzymes, N. D. Rawlings and G. S. Salvesen, (Eds.), Elsevier Science: pp. 800-804. 
Kis-Toth, K., Bacskai, I., Gogolak, P., Mazlo, A., Szatmari, I., and Rajnavolgyi, E. (2013). Monocyte-derived dendritic cell subpopulations use different types of matrix metalloproteinases inhibited by GM6001. Immunobiology 218, 1361-1369.

Knight, C. G., Willenbrock, F., and Murphy, G. (1992). A novel coumarin-labelled peptide for sensitive continuous assays of the matrix metalloproteinases. FEBS Lett. 296, 263266.

Korkmaz, B., Attucci, S., Juliano, M. A., Kalupov, T., Jourdan, M. L., Juliano, L., and Gauthier, F. (2008). Measuring elastase, proteinase 3 and cathepsin $G$ activities at the surface of human neutrophils with fluorescence resonance energy transfer substrates. Nat. Protoc. 3, 991-1000.

Kridel, S. J., Chen, E., Kotra, L. P., Howard, E. W., Mobashery, S., and Smith, J. W. (2001). Substrate hydrolysis by matrix metalloproteinase-9. J. Biol. Chem. 276, 20572-20578.

Kridel, S. J., Sawai, H., Ratnikov, B. I., Chen, E. I., Li, W., Godzik, A., Strongin, A. Y., and Smith, J. W. (2002). A unique substrate binding mode discriminates membrane type-1 matrix metalloproteinase from other matrix metalloproteinases. J. Biol. Chem. 277, 23788-23793.

Lavigne, M. C., Thakker, P., Gunn, J., Wong, A., Miyashiro, J. S., Wasserman, A. M., Wei, S. Q., Pelker, J. W., Kobayashi, M., and Eppihimer, M. J. (2004). Human bronchial epithelial cells express and secrete MMP-12. Biochem. Biophys. Res. Commun. 324, 534-546.

Liu, M., Sun, H., Wang, X., Koike, T., Mishima, H., Ikeda, K., Watanabe, T., Ochiai, N., and Fan, J. (2004). Association of increased expression of macrophage elastase (matrix metalloproteinase 12) with rheumatoid arthritis. Arthritis Rheum. 50, 3112-3117.

London, N., Raveh, B., Cohen, E., Fathi, G., and Schueler-Furman, O. (2011). Rosetta FlexPepDock web server--high resolution modeling of peptide-protein interactions. Nucleic Acids Res. 39, W249-253.

Marchant, D. J., Bellac, C. L., Moraes, T. J., Wadsworth, S. J., Dufour, A., Butler, G. S., Bilawchuk, L. M., Hendry, R. G., Robertson, A. G., Cheung, C. T., Ng, J., Ang, L., Luo, Z., Heilbron, K., Norris, M. J., Duan, W., Bucyk, T., Karpov, A., Devel, L., Georgiadis, D., Hegele, R. G., Luo, H., Granville, D. J., Dive, V., McManus, B. M., and Overall, C. M. (2014). A new transcriptional role for matrix metalloproteinase-12 in antiviral immunity. Nat. Med. 20, 493-502.

Matsumoto, S., Kobayashi, T., Katoh, M., Saito, S., Ikeda, Y., Kobori, M., Masuho, Y., and Watanabe, T. (1998). Expression and localization of matrix metalloproteinase-12 in the aorta of cholesterol-fed rabbits: relationship to lesion development. Am. J. Pathol. 153, 109-119.

Molet, S., Belleguic, C., Lena, H., Germain, N., Bertrand, C. P., Shapiro, S. D., Planquois, J. M., Delaval, P., and Lagente, V. (2005). Increase in macrophage elastase (MMP-12) in lungs from patients with chronic obstructive pulmonary disease. Inflamm Res. 54, 3136 .

Neumann, U., Kubota, H., Frei, K., Ganu, V., and Leppert, D. (2004). Characterization of Mca-Lys-Pro-Leu-Gly-Leu-Dpa-Ala-Arg-NH2, a fluorogenic substrate with increased specificity constants for collagenases and tumor necrosis factor converting enzyme. Anal Biochem. 328, 166-173. 
Palmier, M. O., and Van Doren, S. R. (2007). Rapid determination of enzyme kinetics from fluorescence: overcoming the inner filter effect. Anal. Biochem. 371, 43-51.

Ratnikov, B. I., Cieplak, P., Gramatikoff, K., Pierce, J., Eroshkin, A., Igarashi, Y., Kazanov, M., Sun, Q., Godzik, A., Osterman, A., Stec, B., Strongin, A., and Smith, J. W. (2014). Basis for substrate recognition and distinction by matrix metalloproteinases. Proc. Natl. Acad. Sci. USA 111, E4148-4155.

Rawlings, N. D., Waller, M., Barrett, A. J., and Bateman, A. (2014). MEROPS: the database of proteolytic enzymes, their substrates and inhibitors. Nucleic Acids Res. 42, D503509 .

Schechter, I., and Berger, A. (1967). On the size of the active site in proteases. I. Papain. Biochem. Biophys. Res. Commun. 27, 157-162.

Schirmer, H., Basso da Silva, L., Teixeira, P. J., Moreira, J. S., Moreira, A. L., and Simon, D. (2009). Matrix metalloproteinase gene polymorphisms: lack of association with chronic obstructive pulmonary disease in a Brazilian population. Genet. Mol. Res. 8, 10281034.

Shapiro, S. D. (2000). Animal models for chronic obstructive pulmonary disease: age of klotho and marlboro mice. Am. J. Respir. Cell. Mol. Biol. 22, 4-7.

Shapiro, S. D. (2003). Proteolysis in the lung. Eur. Respir. J. 44 (Suppl.), 30s-32s.

Shapiro, S. D., Kobayashi, D. K., and Ley, T. J. (1993). Cloning and characterization of a unique elastolytic metalloproteinase produced by human alveolar macrophages. J. Biol. Chem. 268, 23824-23829.

Shipley, J. M., Wesselschmidt, R. L., Kobayashi, D. K., Ley, T. J., and Shapiro, S. D. (1996). Metalloelastase is required for macrophage-mediated proteolysis and matrix invasion in mice. Proc. Natl. Acad. Sci. USA 93, 3942-3946.

Taddese, S., Jung, M. C., Ihling, C., Heinz, A., Neubert, R. H., and Schmelzer, C. E. (2009). MMP-12 catalytic domain recognizes and cleaves at multiple sites in human skin collagen type I and type III. Biochim. Biophys. Acta 1804, 731-739.

Taddese, S., Jung, M. C., Ihling, C., Heinz, A., Neubert, R. H., and Schmelzer, C. E. (2010). MMP-12 catalytic domain recognizes and cleaves at multiple sites in human skin collagen type I and type III. Biochim. Biophys. Acta 1804, 731-739.

Taddese, S., Weiss, A. S., Jahreis, G., Neubert, R. H., and Schmelzer, C. E. (2009). In vitro degradation of human tropoelastin by MMP-12 and the generation of matrikines from domain 24. Matrix Biol. 28, 84-91.

Wallace, A. M., and Sandford, A. J. (2002). Genetic polymorphisms of matrix metalloproteinases: functional importance in the development of chronic obstructive pulmonary disease? Am. J. Pharmacogenomics 2, 167-175.

Wang, X., Liang, J., Koike, T., Sun, H., Ichikawa, T., Kitajima, S., Morimoto, M., Shikama, H., Watanabe, T., Sasaguri, Y., and Fan, J. (2004). Overexpression of human matrix metalloproteinase-12 enhances the development of inflammatory arthritis in transgenic rabbits. Am. J. Pathol. 165, 1375-1383.

Zhou, H., Wu, Y., Jin, Y., Zhou, J., Zhang, C., Che, L., Jing, J., Chen, Z., Li, W., and Shen, H. (2013). Genetic polymorphism of matrix metalloproteinase family and chronic obstructive pulmonary disease susceptibility: a meta-analysis. Sci. Rep. 3, 2818. 
Tables and figures

Table 1 Abz-peptidyl-EDDnp fluorogenic substrates designed from sequence analysis of human MMP-12 cleavage sites as detailed in Figure 1 (Groups I, II and III) and from regions spanning cleavage sites by MMP-12 in natural protein substrates (Group IV).

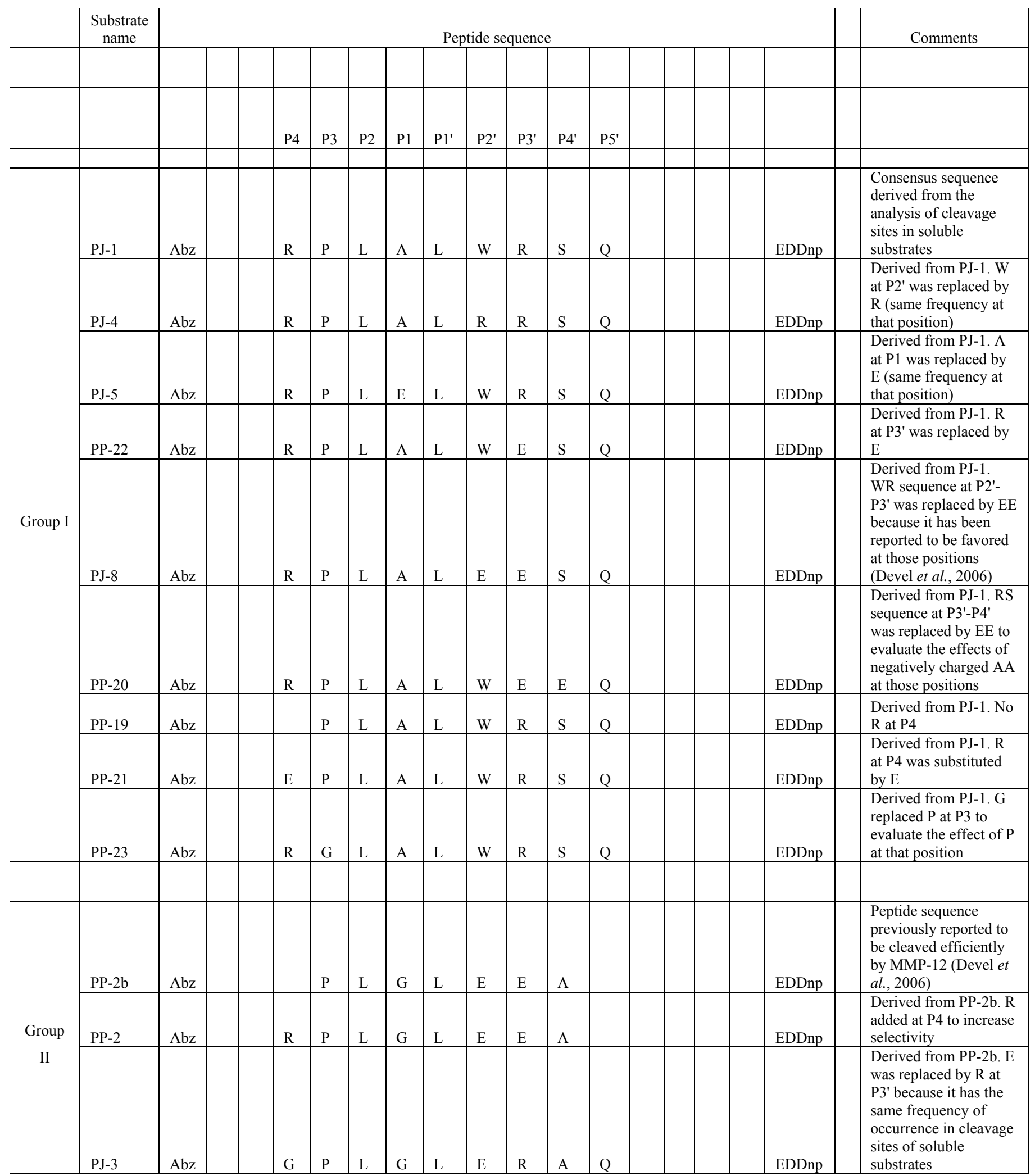




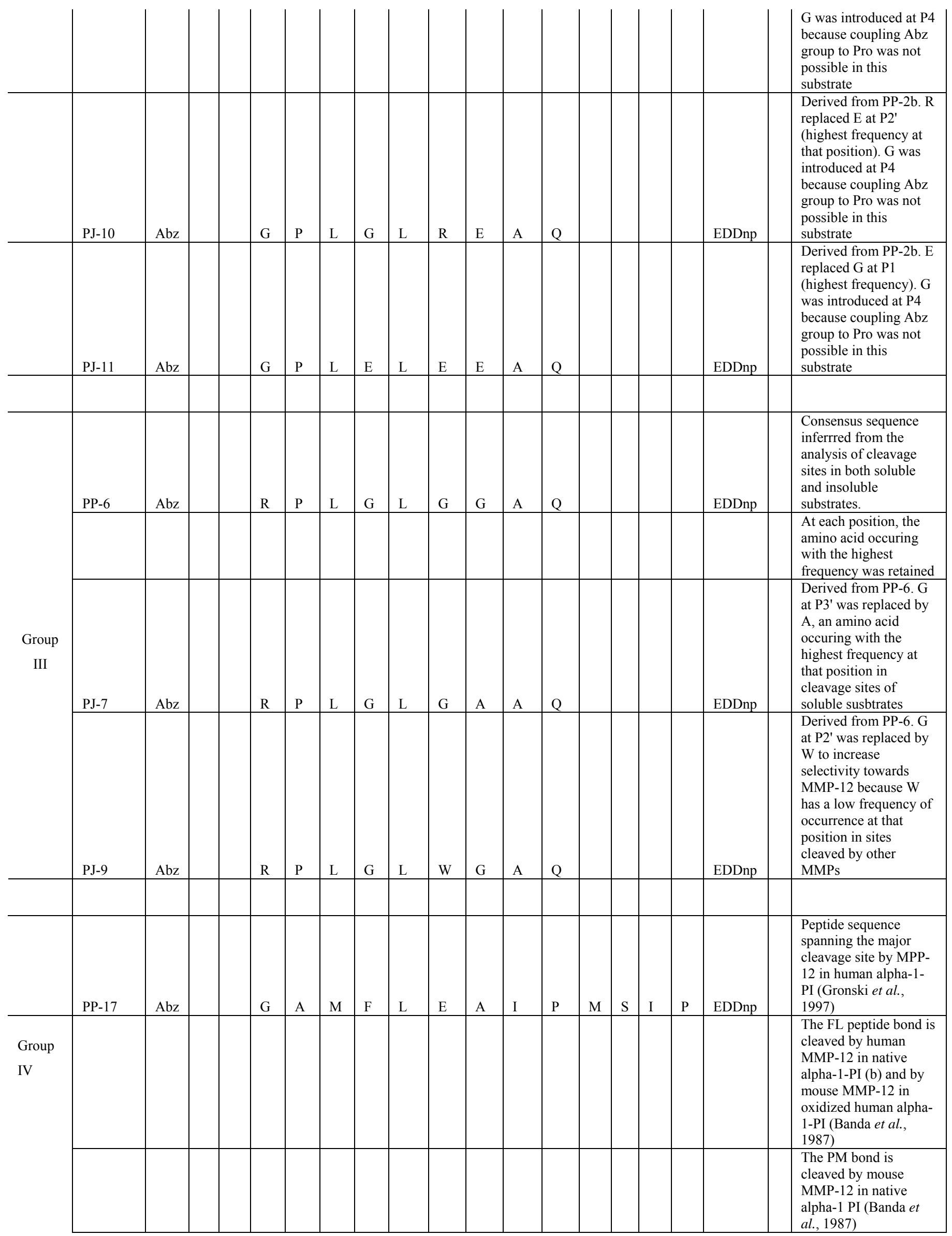




\begin{tabular}{|c|c|c|c|c|c|c|c|c|c|c|c|c|c|c|c|}
\hline PP-14 & $\mathrm{Abz}$ & A & $\mathrm{S}$ & V & A & $\mathrm{T}$ & E & $\mathrm{L}$ & $\mathrm{R}$ & A & Q & & & EDDnp & $\begin{array}{l}\text { Peptide sequence } \\
\text { spanning human MPP- } \\
12 \text { cleavage site in } \\
\text { human CXCL1 (Dean } \\
\text { et al., 2008) }\end{array}$ \\
\hline PP-15 & $\mathrm{Abz}$ & E & A & A & $\mathrm{P}$ & $\mathrm{S}$ & $\mathrm{S}$ & V & I & A & A & $\mathrm{T}$ & E & EDDnp & $\begin{array}{l}\text { Peptide sequence } \\
\text { spanning human MPP- } \\
12 \text { cleavage site in } \\
\text { murine CXCL5 (Dean } \\
\text { et al., 2008) }\end{array}$ \\
\hline PP-16 & Abz & & $\mathrm{R}$ & $\mathrm{N}$ & A & $\mathrm{L}$ & A & V & E & $\mathrm{R}$ & $\mathrm{T}$ & A & $\mathrm{S}$ & EDDnp & $\begin{array}{l}\text { Peptide sequence } \\
\text { spanning human MPP- } \\
12 \text { cleavage site in } \\
\text { murine CXCL5 (Dean } \\
\text { et al., 2008) }\end{array}$ \\
\hline
\end{tabular}

Table 2 Specificity constants $k_{\text {cat }} / K_{m}$ for the hydrolysis of Abz-peptidyl-EDDnp fluorogenic substrates by MMP12s.

\begin{tabular}{|c|c|c|c|}
\hline \multicolumn{4}{|c|}{$k_{\mathrm{cat}} / K_{m}$} \\
\hline h-CAT-MMP-12 & h-FL-MMP-12 & $\begin{array}{c}\text { m-CAT-MMP- } \\
12\end{array}$ & m-FL-MMP-12 \\
\hline
\end{tabular}

$\mathrm{mM}^{-1} \mathrm{~s}^{-1}$

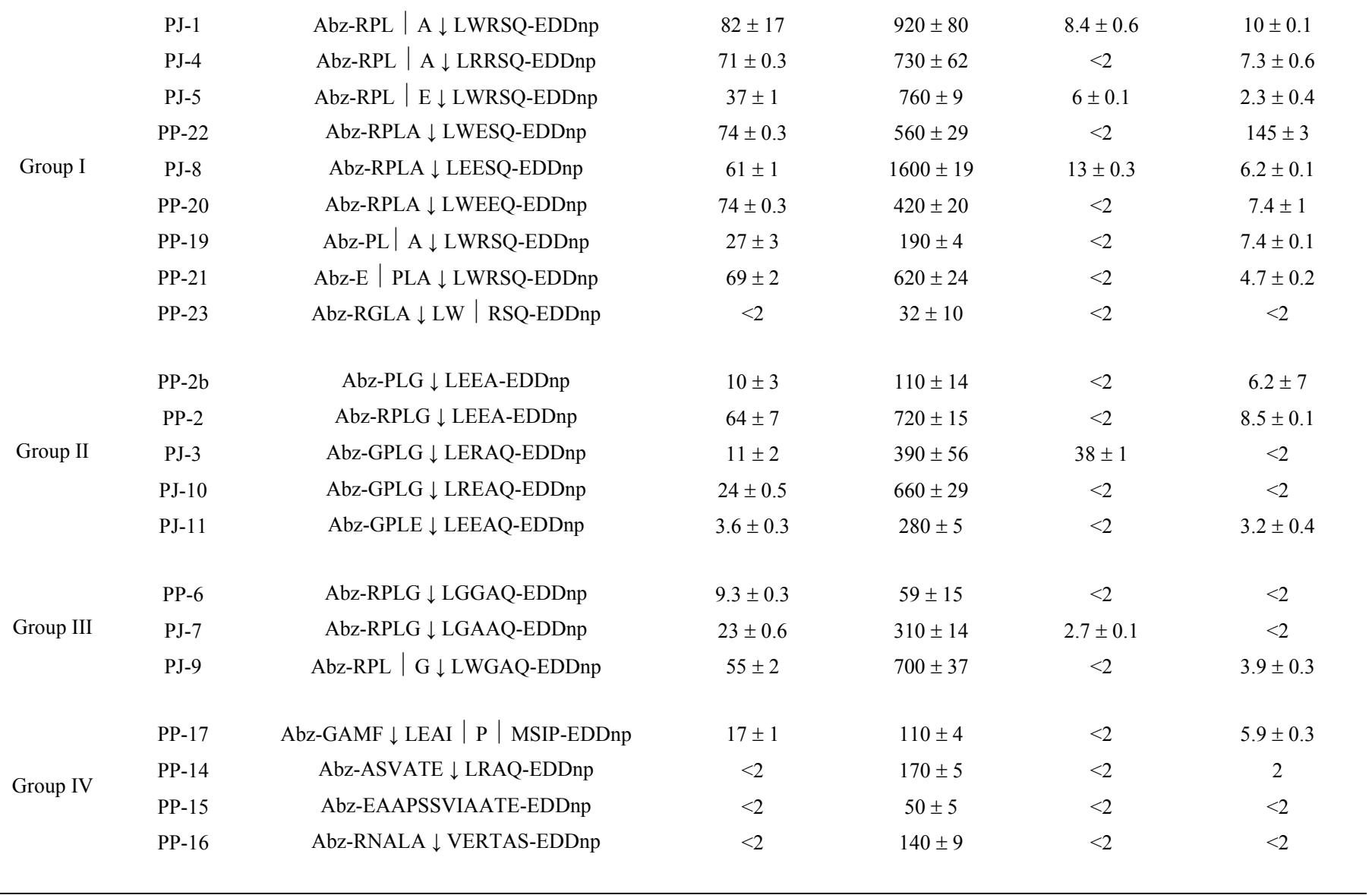

Specificity constants were determined under first-order conditions for the hydrolysis of fluorogenic substrates by human catalytic domain of MMP-12 (h-CAT-MMP-12), human full-length MMP-12 (h-FL-MMP-12), murine catalytic domain of MMP-12 (m-CAT-MMP-12) and 
murine full-length MMP-12 (m-FL-MMP12). $\downarrow$ and $\mid$ indicate major and secondary minor cleavage sites by human MMP-12 respectively. Minor cleavage sites represented less than $5 \%$ of the primary cleavage site as assessed from HLPC profiles. Results are shown as an average \pm standard deviation (S.D.) of a minimum of two distinct experiments.

Table 3 Kinetic data $\left(K_{\mathrm{m}}, k_{\mathrm{cat}}\right.$ and $\left.k_{\mathrm{cat}} / K_{\mathrm{m}}\right)$ for the hydrolysis of selected Abz-peptidylEDDnp fluorogenic substrates by human MMP-12.

$\begin{array}{lccccccccc}\text { PJ-1 } & \text { Abz-RPLALWRSQ-EDDnp } & 14.4 & 0.33 & 23 & 82 & 15.6 & 5.6 & 359 & 920 \\ \text { PJ-5 } & \text { Abz-RPLELWRSQ-EDDnp } & 9.3 & 0.14 & 15 & 37 & 8.8 & 1.4 & 159 & 760 \\ \text { PP-22 } & \text { Abz-RPLALWESQ-EDDnp } & 6.8 & 0.11 & 17 & 74 & 13.8 & 2.8 & 203 & 560 \\ \text { PJ-8 } & \text { Abz-RPLALEESQ-EDDnp } & 29.0 & 0.26 & 9 & 61 & 7.5 & 2.4 & 320 & 1600 \\ \text { PP-20 } & \text { Abz-RPLALWEEQ-EDDnp } & 14.6 & 0.17 & 12 & 74 & 12.3 & 1.3 & 106 & 420 \\ \text { PP-19 } & \text { Abz-PLALWRSQ-EDDnp } & 20.2 & 0.85 & 42 & 27 & 24.9 & 1.5 & 60 & 190 \\ & & & & & & & & & \\ \text { PP-2b } & \text { Abz-PLGLEEA-EDDnp } & 9.1 & 0.29 & 32 & 10 & 4.7 & 0.55 & 117 & 110 \\ \text { PP-2 } & \text { Abz-RPLGLEEA-EDDnp } & 10.3 & 0.19 & 18 & 64 & 19.7 & 3.8 & 193 & 720\end{array}$

Individual parameters $\left(K_{\mathrm{m}}, k_{\mathrm{cat}}\right)$ for the hydrolysis of the catalytic domain of human MMP-12 (h-CAT-MMP-12) and full-length human MMP-12 (h-FL-MMP-12) were determined using increasing concentrations of substrate (0.5-20 $\mu \mathrm{M})$. Data were fitted to the MichaelisMenten equation using Graph Pad Prism software. Results are shown as averages of at least two distinct experiments. Standard errors for $k_{\text {cat }}$ and $K_{m}$ determinations were $<10 \%$ and were not indicated for the sake of clarity.

$* k_{\text {cat }} / K_{\mathrm{m}}$ values as determined under first-order conditions (see Table 2 ).

Table 4 Specificity constants $k_{\text {cat }} / K_{\mathrm{m}}$ for the hydrolysis of Abz-peptidyl-EDDnp fluorogenic substrates by human MMPs.

\begin{tabular}{|c|c|c|c|c|c|c|}
\hline & & \multicolumn{5}{|c|}{$k_{\mathrm{cat}} / K_{\mathrm{m}}$} \\
\hline & & MMP-12 & MMP-2 & MMP-7 & MMP-9 & MMP-13 \\
\hline & & \multicolumn{5}{|c|}{$\mathrm{mM}^{-1} \mathrm{~s}^{-1}$} \\
\hline PJ-1 & Abz-RPLALWRSQ-EDDnp & $920 \pm 80$ & $191 \pm 15$ & $151 \pm 3$ & $<2$ & $989 \pm 37$ \\
\hline PJ-4 & Abz-RPLALRRSQ-EDDnp & $730 \pm 62$ & $377 \pm 49$ & $395 \pm 9$ & $291 \pm 14$ & $2730 \pm 528$ \\
\hline PJ-5 & Abz-RPLELWRSQ-EDDnp & $760 \pm 9$ & $32 \pm 7$ & $87 \pm 3$ & $67 \pm 1$ & $140 \pm 6$ \\
\hline PP-22 & Abz-RPLALWESQ-EDDnp & $560 \pm 29$ & $285 \pm 33$ & $142 \pm 8$ & $198 \pm 54$ & $4420 \pm 301$ \\
\hline PJ-8 & Abz-RPLALEESQ-EDDnp & $1600 \pm 19$ & $20 \pm 8$ & $119 \pm 2$ & $21 \pm 1$ & $336 \pm 34$ \\
\hline PP-20 & Abz-RPLALWEEQ-EDDnp & $420 \pm 20$ & $136 \pm 2$ & $133 \pm 4$ & $143 \pm 2$ & $1390 \pm 109$ \\
\hline PP-19 & Abz-PLALWRSQ-EDDnp & $190 \pm 4$ & $93 \pm 2$ & $24 \pm 10$ & $51 \pm 1$ & $47 \pm 6$ \\
\hline PP-21 & Abz-EPLALWRSQ-EDDnp & $620 \pm 24$ & $269 \pm 8$ & $59 \pm 6$ & $71 \pm 10$ & $1200 \pm 129$ \\
\hline
\end{tabular}




$\begin{array}{llccccc}\text { PP-23 } & \text { Abz-RGLALWRSQ-EDDnp } & 32 \pm 10 & 10 \pm 5 & <2 & <2 & <2 \\ \text { PP-2b } & \text { Abz-PLGLEEA-EDDnp } & & & & 135 \pm 1 \\ \text { PP-2 } & \text { Abz-RPLGLEEA-EDDnp } & 110 \pm 14 & 12 \pm 1 & <2 & 8 \pm 3 & 640 \pm 14 \\ \text { PJ-3 } & \text { Abz-GPLGLERAQ-EDDnp } & 720 \pm 15 & 106 \pm 6 & 80 \pm 7 & 62 \pm 1 & 133 \pm 11 \\ \text { PJ-10 } & \text { Abz-GPLGLREAQ-EDDnp } & 390 \pm 56 & 75 \pm 5 & 30 \pm 1 & 14 \pm 5 & 1620 \pm 121 \\ \text { PJ-11 } & \text { Abz-GPLELEEAQ-EDDnp } & 660 \pm 29 & 216 \pm 5 & 184 \pm 15 & 160 \pm 8 & 62 \pm 10 \\ & & 280 \pm 5 & <2 & 73 \pm 8 & <2 & 273 \pm 25 \\ \text { PP-6 } & \text { Abz-RPLGLGGAQ-EDDnp } & & & & & 905 \pm 61 \\ \text { PJ-7 } & \text { Abz-RPLGLGAAQ-EDDnp } & 59 \pm 15 & 139 \pm 8 & 8 \pm 2 & 270 \pm 14 & 2750 \pm 91 \\ \text { PJ-9 } & \text { Abz-RPLGLWGAQ-EDDnp } & 310 \pm 14 & 86 \pm 7 & 56 \pm 5 & 133 \pm 5 & 140 \pm 6 \\ & & 700 \pm 37 & 797 \pm 62 & 227 \pm 3 & 750 \pm 37 & 87 \pm 8 \\ \text { PP-17 } & \text { Abz-GAMFLEAIPMSIP-EDDnp } & 110 \pm 4 & <2 & 33 \pm 1 & 15 \pm 7 & <2 \\ \text { PP-14 } & \text { Abz-ASVATELRAQ-EDDnp } & 170 \pm 5 & 43 \pm 1 & 33 \pm 1 & <2 & <2 \\ \text { PP-15 } & \text { Abz-EAAPSSVIAATE-EDDnp } & 50 \pm 5 & 70 \pm 1 & <2 & <2 & <2 \\ \text { PP-16 } & \text { Abz-RNALAVERTAS-EDDnp } & 140 \pm 9 & <2 & <2 & <2 & <2\end{array}$

$k_{\text {cat }} / K_{\mathrm{m}}$ values for the hydrolysis of all 21 substrates designed in this study by the full-length form of MMP-2, MMP-7, MMP-9 and MMP-13 were determined under first-order conditions and compared with those obtained for full-length MMP-12 (first column). Values are means \pm SD of at least two distinct experiments.

A

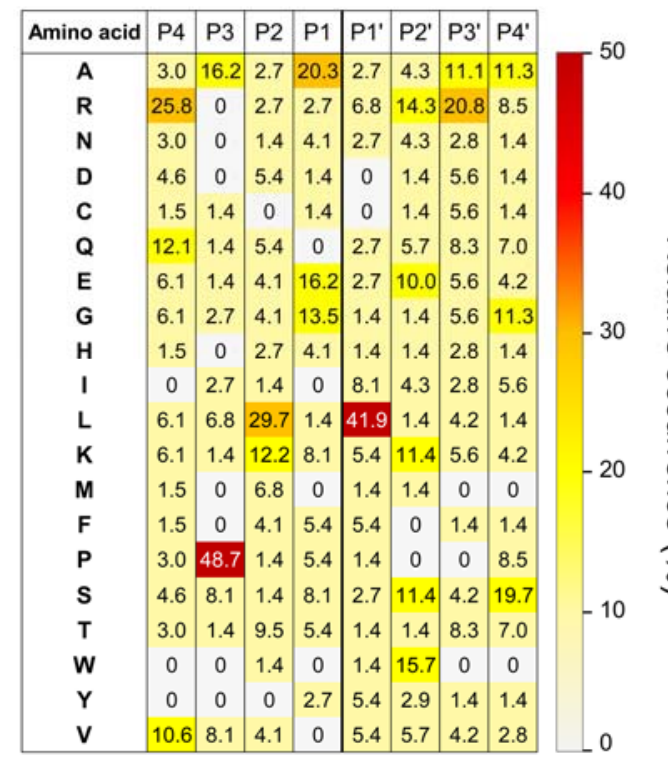

B

\begin{tabular}{|c|c|c|c|c|c|c|c|c|c|}
\hline Amino acid & P4 & P3 & P2 & P1 & P1' & P2' & P3' & P4' & \\
\hline A & 17.7 & 26.7 & 30.7 & 24.4 & 16.5 & 19.9 & 30.1 & 25.6 & \\
\hline $\mathbf{R}$ & 1.7 & 0.6 & 1.7 & 1.7 & 0 & 4.6 & 0.6 & 2.3 & \\
\hline N & 2.3 & 1.1 & 0.6 & 2.8 & 0 & 1.7 & 1.1 & 3.4 & \\
\hline D & 0.6 & 0 & 0 & 0.6 & 1.1 & 0.6 & 1.1 & 1.7 & -40 \\
\hline C & 0.6 & 0 & 0 & 0 & 0.6 & 0.6 & 0 & 0.6 & \\
\hline $\mathbf{Q}$ & 1.1 & 3.4 & 5.1 & 3.4 & 2.8 & 4.0 & 1.1 & 2.8 & \\
\hline E & 1.7 & 1.7 & 5.1 & 1.1 & 0.6 & 1.7 & 1.1 & 2.3 & \\
\hline G & 33.1 & 13.6 & 24.43 & 39.8 & 3.4 & 28.4 & 33.5 & 15.3 & -30 \\
\hline $\mathbf{H}$ & 0.6 & 0.6 & 1.1 & 1.7 & 0.6 & 1.1 & 0 & 0 & \\
\hline 1 & 1.7 & 1.1 & 1.7 & 0.6 & 6.8 & 2.8 & 1.7 & 4,0 & \\
\hline L & 7.4 & 9.1 & 6.3 & 2.3 & 31.3 & 3.4 & 6.3 & 9.1 & \\
\hline$K$ & 8.6 & 1.1 & 3.4 & 6.3 & 7.4 & 8.5 & 1.7 & 4,0 & -2 \\
\hline$M$ & 0 & 0 & 0 & 0.6 & 0.6 & 0.6 & 0 & 0.6 & \\
\hline $\mathbf{F}$ & 1.1 & 0.6 & 5.1 & 1.1 & 4.0 & 3.4 & 2.3 & 3.4 & \\
\hline $\mathbf{P}$ & 7.4 & 31.8 & 6.3 & 6.3 & 2.8 & 2.3 & 4.6 & 10.2 & \\
\hline s & 1.7 & 1.1 & 2.8 & 1.1 & 1.7 & 4.0 & 4.0 & 2.8 & -10 \\
\hline $\mathbf{T}$ & 2.3 & 1.7 & 0.6 & 1.1 & 2.3 & 4.0 & 2.8 & 2.3 & \\
\hline w & 0 & 0 & 0 & 0 & 0.6 & 0 & 0.6 & 0 & \\
\hline $\mathbf{Y}$ & 1.7 & 0.6 & 3.4 & 0.6 & 6.8 & 1.7 & 3.4 & 1.1 & \\
\hline v & 8.6 & 5.1 & 1.7 & 4.6 & \begin{tabular}{|l|} 
\\
10.2
\end{tabular} & 6.8 & 4.0 & 8.5 & L 0 \\
\hline
\end{tabular}

Figure 1 Frequencies of amino acids around the substrate sites cleaved by human MMP-12

We determined the frequency of each amino acid from positions P4 to P4' within the 74 unique cleavage sites of 44 distinct soluble substrates of MMP-12 (A) and the 176 cleavage sites in 16 distinct structural proteins (B). The scissile peptide bond is cleaved between residues $\mathrm{P} 1$ and $\mathrm{P} 1$ '. Data are visualized using a heat map-like representation where the color 
spectrum defines the relative frequency of each amino acid from low (light grey) to high (red). Details of this analysis are given in Table S1 (Supplementary Information).
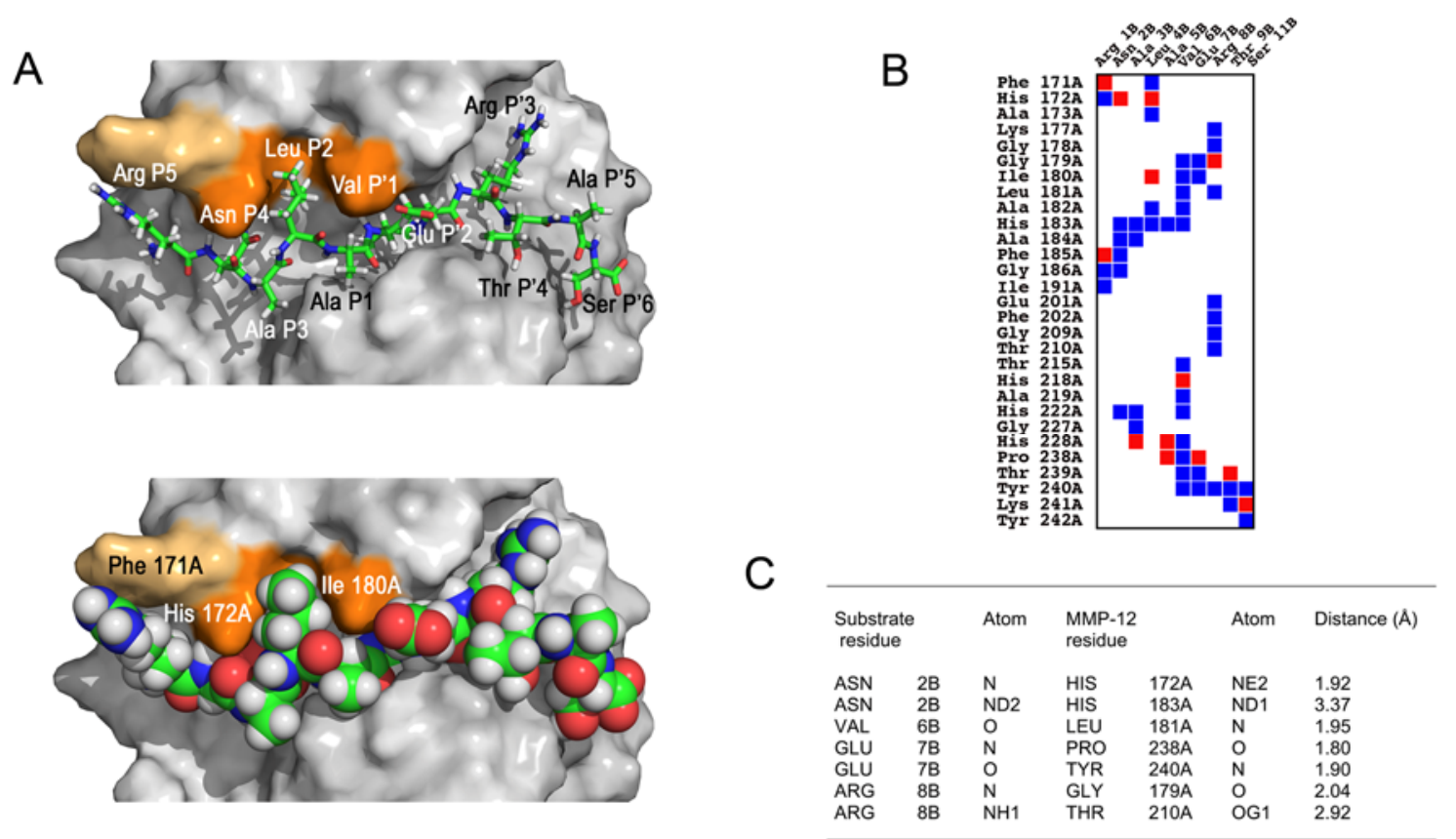

Figure 2 Docking model of RNALAVERTAS peptide in the MMP-12 active site.

(A) The peptide was docked in the active site of MMP-12 using FlexPepDock (see materials and methods). MMP-12 is shown with its solvent-accessible surface colored grey and in standard orientation; the modeled peptide substrate RNALA $\downarrow$ VERTAS is represented in sticks (top) or CPK (bottom). The atoms of the peptide are colored green (carbon), red (oxygen), blue (nitrogen), and light grey (hydrogen). The enzyme residues His 172A and Ile 180A that form a hydrophobic sandwich accommodating the peptide substrate P2 Leu residue are colored orange, while enzyme residue Phe 171A that interacts strongly with substrate P5 Arg is in light orange. (B) Contact map analysis of all interactions between the RNALAVERTAS peptide and MMP-12 residues, as calculated with CMA (http://ligin.weizmann.ac.il/cma/). Contact areas $<30 \AA$ are shown in blue while those $>30 \AA$ are red. (C) Hydrogen bonds between peptide residues and MMP-12 residues, calculated using the program HBOND (http://cib.cf.ocha.ac.jp/bitool/HBOND/). 
A

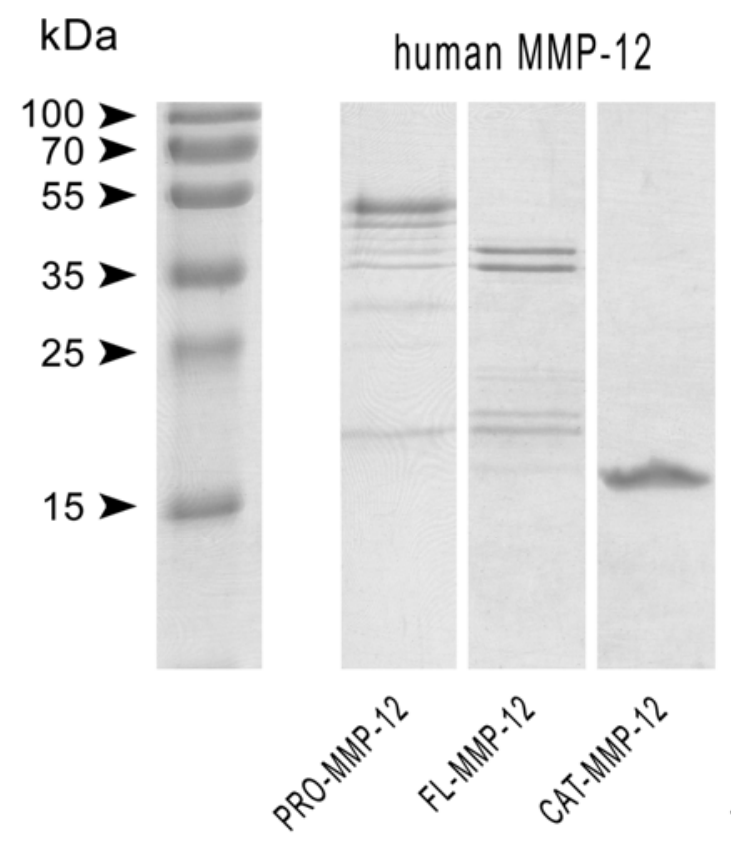

B mouse MMP-12
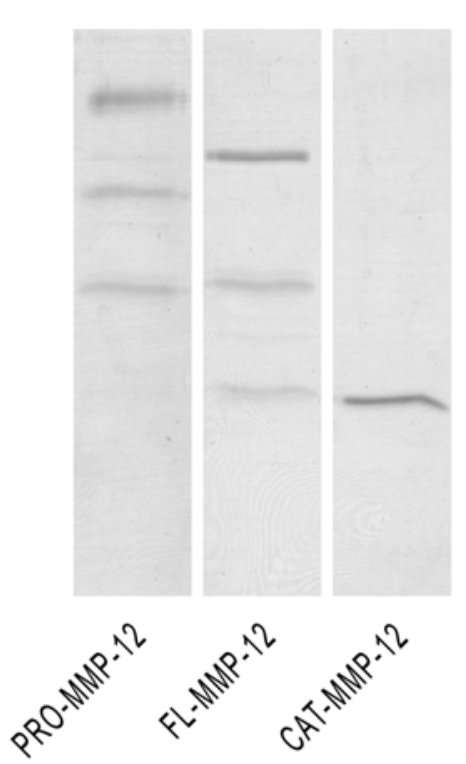

Figure S1 SDS-PAGE analysis of the various forms of human and mouse MMP-12.

The proform of MMP-12 (PRO-MMP-12) was converted to the full length form (FL-MMP12) by 4-aminophenylmercuric acetate (APMA) treatment following the supplier's instructions. Human and mouse pro-MMP-12 were incubated with $1 \mathrm{mM}$ APMA at $37{ }^{\circ} \mathrm{C}$ for $1 \mathrm{~h}$ and $24 \mathrm{~h}$ respectively in $50 \mathrm{mM}$ Tris- $\mathrm{HCl}$ buffer, $\mathrm{pH} 7.5,10 \mathrm{mM} \mathrm{CaCl}_{2}, 150 \mathrm{mM} \mathrm{NaCl}$, $0.05 \%(w / v)$ Brij 35. For mouse MMP-12, $5 \mu \mathrm{M} \mathrm{ZnCl}_{2}$ was added in the activation buffer.

The His-tagged catalytic domain of human or mouse MMP-12 (CAT-MMP-12) was expressed in E. coli expression system and purified by affinity chromatography as detailed in the Materials and Methods section.

Human (A) and mouse (B) forms of MMP-12 (1 $\mu \mathrm{g})$ were loaded onto a $15 \%$ SDS polyacrylamide gel (non reducing conditions) and coloured with Coomassie Blue G250. 